\title{
Fresnel-based modular solar fields for performance/cost optimization in solar thermal power plants: A comparison with parabolic trough collectors
}

\author{
Hani H. Sait ${ }^{\mathrm{a}, 1}$, Jose M. Martinez-Val ${ }^{\mathrm{b}, *}$, Ruben Abbas ${ }^{\mathrm{b}}$, Javier Munoz-Anton ${ }^{\mathrm{b}}$ \\ ${ }^{a}$ Mechanical Engineering Department, King Abdulaziz University-Rabigh, P.O. Box 344, Rabigh 21911, Saudi Arabia \\ ${ }^{\mathrm{b}}$ Jose Gutierrez Abascal, 228006 Madrid, Spain
}

\section{H I G H L I G H T S}

- Fresnel reflectors radiation concentration factors can be increased by accurate design.

- Multi-tube, multi-pass receivers are highly efficient in absorbing concentrated radiation.

- Structural analysis is the basis for minimizing weight and complexity of the plant.

- Specific investment cost of Fresnel plants can be in the range of $2-3 \mathrm{e} / \mathrm{W}$.
Keywords:

Fresnel reflectors

Concentrating radiation

Multi-tube receivers

Minimizing structures

\section{G R A P H I C A L A B S T R A C T}

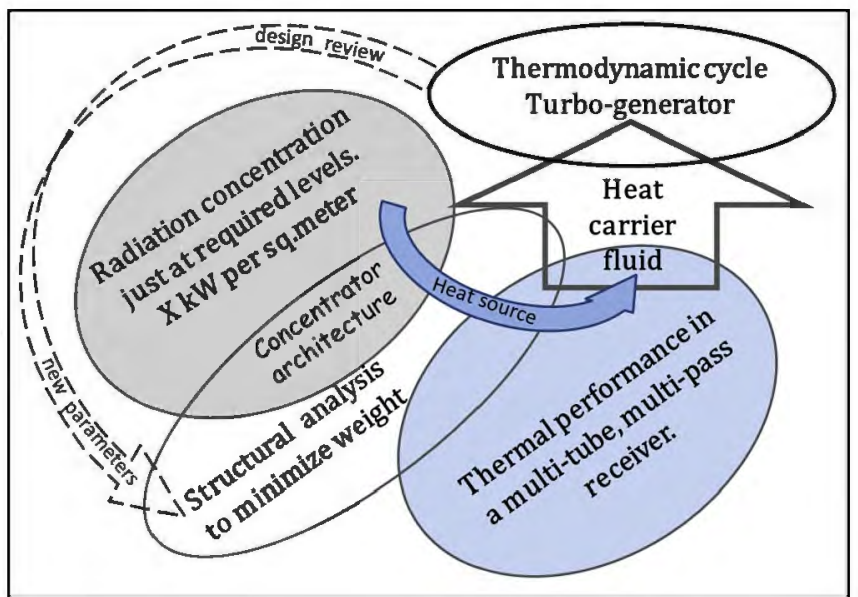

\section{A B S T R A C T}

Linear Fresnel collectors are identified as a technology that should play a main role in order to reduce cost of Concentrating Solar Power. An optical and thermal analysis of the different blocks of the solar power plant is carried out, where Fresnel arrays are compared with the most extended linear technology: parabolic trough collectors. It is demonstrated that the optical performance of Fresnel arгay is very close to that of PTC, with similar values of maximum flux intensities. In addition, if the heat carrier fluid flows in series by the tubes of the receiver, relatively high thermal efficiencies are achieved. Thus, an annual solar to electricity efficiency of $19 \%$ is expected, which is similar to the state of the art in PTCs; this is done with a reduction of costs, thanks to lighter structures, that drives to an estimation of LCOE of around $6.5 \mathrm{c} \in / \mathrm{kWh}$. (c) 2014 Elsevier Ltd. All rights reserved,

\section{Introduction, background and objective of the study}

The use of renewable energies for power generation is main issue it today's society in order to avoid energy dependence and

\footnotetext{
* Corresponding author.

1 Tel.: +966560007382.
}

reduce the impact of greenhouse emissions [1]. It is of paramount importance to use such renewable sources in an economically efficient way, and CSP is one of the technologies that may best help to do it in countries with high solar radiations levels [1]. Compared to photovoltaic technology, it seems that CSP can achieve this option with lower costs [2], although more land use is required [3]. 


\section{Nomenclature}

$\begin{array}{ll}\alpha & \text { mirror-receiver angle } \\ A & \text { cross section area } \\ A_{f} & \text { receiver's surface in contact with the fluid } \\ A_{S} & \text { receiver's surface where radiation impinges } \\ A_{w} & \text { window surface } \\ b & \text { length of the side of the square section of a prism } \\ \beta & \text { mirror incidence angle } \\ d & \text { distance from receiver's pole to center of mirror } \\ D & \text { receiver diameter } \\ E & \text { elastic modulus } \\ \varepsilon_{S} & \text { receiver surface effective emissivity } \\ \varepsilon_{w} & \text { window surface effective emissivity } \\ \eta & \text { energy efficiency } \\ \eta \text {-exerg } & \text { exergy efficiency } \\ f & \text { maximum deflection of a beam with fixed ends } \\ F & \text { total radiation intercepted by Fresnel collector } \\ \gamma & \text { zenithal angle } \\ \gamma^{*} & \text { maximum zenithal angle considered } \\ H & \text { Fresnel receiver height } \\ I & \text { moment of inertia } \\ L & \text { receiver length } \\ p & \text { quadratic term in a parametric expression }\end{array}$

$\begin{array}{ll}q & \text { linear term in a parametric expression } \\ Q_{t} & \text { impinging radiation on the receiver } \\ S & \text { linear mass density of the supporting structures } \\ r & \text { inverse term } \\ \sigma & \text { Stephan-Boltzmann constant, } 5.67 \cdot 10^{-8} \mathrm{~W} /\left(\mathrm{K}^{4} \mathrm{~m}^{2}\right) \\ \theta & \text { half the zenithal angle } \\ t & \text { thickness of the square section of a prism } \\ T & \text { total radiation intercepted by troughs collectors } \\ T_{e} & \text { environment temperature } \\ T_{f} & \text { fluid temperature leaving the solar field } \\ T_{s} & \text { receiver surface temperature } \\ T_{w} & \text { receiver window temperature } \\ u & \text { useful linear mass density } \\ U_{e} & \text { integrated convection coefficient from the window to } \\ U_{f} & \text { the environment } \\ & \text { transmission coefficient from the surface to the heat } \\ U_{w} & \text { carrier fluid } \\ & \text { integrated convection coefficient from the surface to the } \\ w & \text { window } \\ Y & \text { total linear load } \\ Y_{b} & \text { total linear weight of the beam }\end{array}$

Although most of current installed solar plants use parabolic trough collector (PTC) technology, linear Fresnel collectors arise with $12.9 \%$ of installed capacity [4]. However, it is still a developing technology, which far from its optimum design at current time. The structure of a CSP installation follows a well-established structure at conceptual level $[5,6]$, but it has a large number of alternatives for that structure to be materialized into a specific plant. At first, a CSP plant has two main bodies:

- The Solar Field (SF) where the solar radiation is concentrated. Part of such radiation is captured as useful heat, that drives to an enthalpy gained by the fluid (the Heat Carrier Fluid, or $\mathrm{HCF}$ ). Such fluid plays a fundamental role in the performance of the plant and imposes important working conditions, such as the maximum allowable working temperature [4-11]. The present study will mainly focus this part, following the concept of Advanced Fresnel reflectors with multi-tube receiver, developed by this team $[5,6]$.

- The power block (PB) which is the energy conversion unit, mainly based on a thermodynamic cycle. At present, water/ steam Rankine cycles fully dominate this field, with unitary turbine-alternator power in the level from $50 \mathrm{MW}$ (electric) $[12,13]$ to $400 \mathrm{MW}$ [14]. However, recent studies show that Brayton cycles could be developed for CSP applications, with appropriate values of pressure and temperature in the extreme points of the cycle, the hottest at turbine inlet, and the one with the lowest enthalpy at compressor inlet [15]. In addition, at current time other possibilities arise in the research field, such as Kalina cycles for low temperature [16]. Finally, some synergies are sough with solar power boost in a coal fired steam turbine [17], osmosis desalination [18] and chemical loop with gas turbines [19].

The thermodynamic cycle selected for the plant sets up the parameters of the final use of the collected heat. Therefore, the optimization of the SF must take into account the features of the cycle, particularly the range of temperature and how it affects the conversion efficiency. In this study, a commercial Rankine is assumed as PB cycle, with an efficiency of $60 \%$ of the Carnot efficiency (although actual efficiencies also depend on the number of turbine bodies and drains).

This research work is aimed at analyzing a Solar Field based on linear Fresnel reflectors array (FA) which have received so far some attention [20-32] but still have possibilities to be explored, to properly characterize their features for supplying steam at high temperature and pressure, either directly or through an intermediate fluid.

An FA is composed of unitary elements (as mirrors, their supporting structure, the structure of the receivers, schematically shown in Fig. 1). The objective is to identify geometrical and thermal designs with much less use of materials and similar perfor mance level than the reference device, which is the PTC $[33,34]$. Therefore, performance and costs of FAs are compared with PTCs in all sections of this paper.

It is worth noting that the main cost component of a solar power plant is the fixed cost produced by the initial investment. Operation and maintenance are very modest in comparison, because fuel consumption to run the plant does not exists, and the energy needed for pumping the fluids in the plant is accounted for in the net power.

Therefore, the magnitude to be minimized is the total cost of the Solar Field needed to feed the thermal energy for a Power Block. Unitary costs $(\$ / \mathrm{kg})$ of a given material are assumed to be known as boundary conditions established by the general market, because those products[35-38] are structural steel, concrete, pipes and mirrors (which are mainly based on silver-coated glass). Minimizing the amount of mass $(\mathrm{kg})$ needed to make a certain $\mathrm{SF}$ is the main goal of this study.

The selection of Fresnel arrays and multi-tube receivers, such as the one depicted in Fig. 2, must be justified in terms of physical principles, before addressing a detailed analysis of the energy transmission and conversion chain, which must meet the requirements of an integral approach to feature the total system and its performance. Fig. 3 presents an outline of the methodology followed for this work.

Section 2 deals with CSP principles for converting solar radiation energy into enthalpy of the heat carrier fluid (HCF), where radiation concentration of FAs and PTCs [39-41] are considered. 


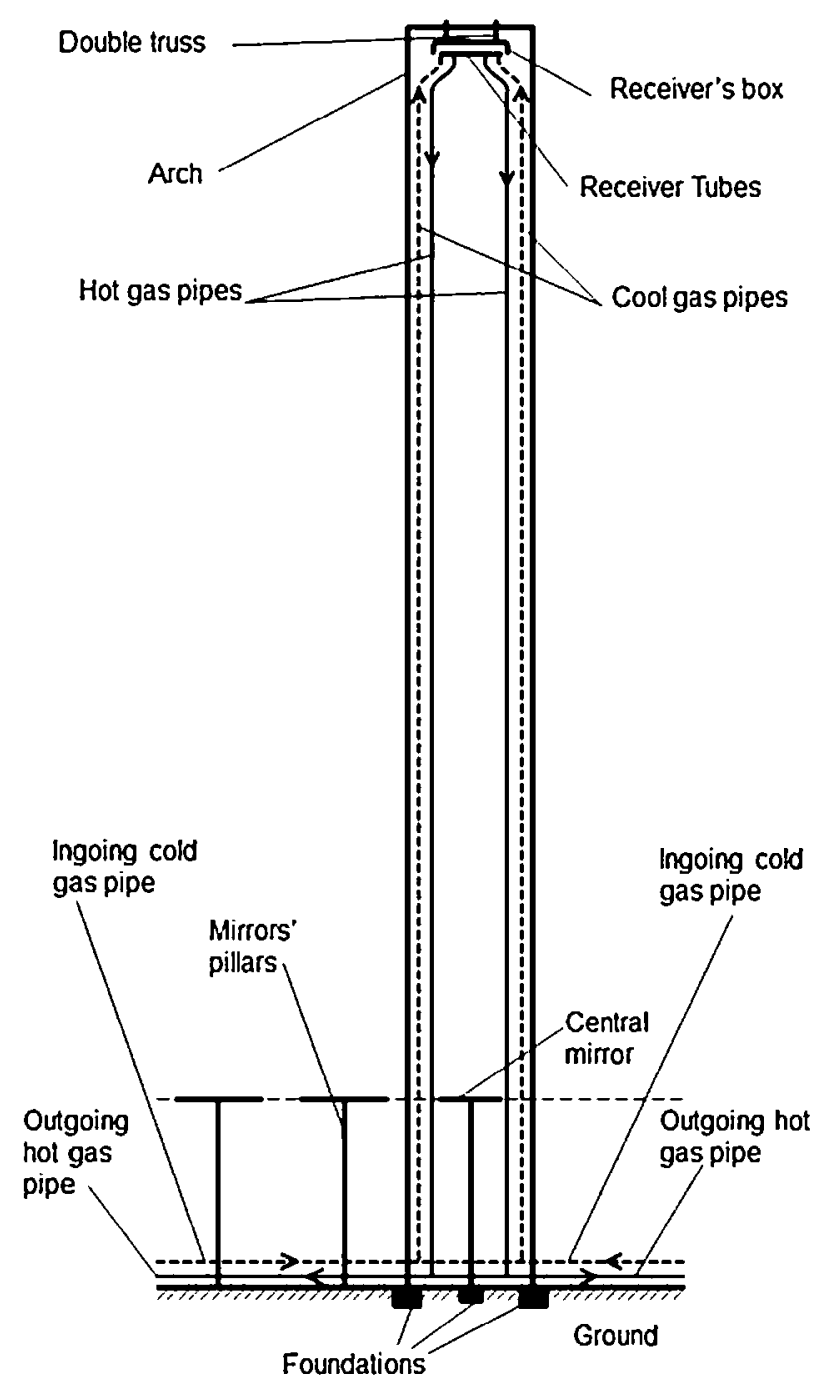

Fig. 1. Main elements of a Fresnel array: mirror, pillars, receiver, arch, pipes. All components are light with simple supporting structure.

Section 3 is devoted to the characterization of radiation concentration from Fresnel arrays onto linear receivers, and Section 4 presents the results of captured energy (at a given temperature) for some selected heat carrier fluids (HCF) to select the best one for our goals. The plant layout and the assembling of all HCF pipes are treated in Section 5.

These sections of the paper are based on extensive numerical simulations of the performance of the different elements of the Solar Field, and their integration into a modular collector which is the modular unit of a full scale SF for a full scale power plant. Nevertheless, fundamental explanations are given on physical grounds, not highly accurate for calculations but useful for direct understanding.

Section 6 briefly presents the basic discussion on the structural analysis of the main components of the plant, and how to take advantage of the Fresnel simplicity to reduce the mass needed for reaching a given value of concentration or thermal features.
Finally, Section 7 presents a justified economic estimate of advanced Fresnel arrays with multi-tube receivers for a plant in the range of $50 \mathrm{MW}(\mathrm{el})$.

These findings can be the base for the construction of some FA modules to assess this potential and the optical and thermal features which support it.

\section{Basic features of linear receivers heated by concentrated radiation}

A fundamental guideline for solar plants optimization is based on the temperature limitations in the critical materials of the energy conversion chain, and the current temperature values for standard and advanced (but available) thermodynamic cycles, which must be properly combined. A key temperature is that of the radiation absorbing surface, $T_{5}$. From said surface, heat should flow to the heat carrier fluid, which leaves the solar field at a temperature $T_{f}$, somehow lower than $T_{s}$. $T_{f}$ characterizes the temperature of the heat source of the thermodynamic cycle, and therefore, the higher it is, the higher the efficiency.

Besides the former route of the energy conversion chain, there is the route of thermal losses, because a fraction of the impinging radiation, $Q_{t}$, will go to the environment, $Q_{e}$. In this route, the most critical thermal link is the glass window covering the receiver container, which in our case can be described as an elongated box containing a bundle of pipes. The box is closed and strongly insulated around the bundle, except in the side of the window, which must be very transparent for the incoming radiation and reflective for the outgoing radiation, and is characterized by a temperature $T_{w}$. The environment surrounding the receiver has a temperature $T_{e}$.

There are several computer codes for studying and simulating the behavior of Fresnel concentrators and linear receivers $[8,9,42]$ and many accurate results have been published so far, and will be presented later on for $\mathrm{CO}_{2}$ as heat carrier fluid. Moreover, some specific installations as Puerto Errado 1 and 2 in Murcia, Spain [31] are directly generating vapor at $300^{\circ} \mathrm{C}$ and are well characterized. However, specific designs are not very suitable for having a broad view of the inherent features of the Fresnel reflector concentration model plus the multi-tube receiver. In fact, this broad and coarse analysis must also be useful for highlighting some relevant features of this type of solar field, namely the radiation intensity needed to reach a range of temperatures in the heat carrier fluid.

The first version of this analysis will be a thermal energy balance in the final section of the receiver, where the temperature of the absorbing surface, $T_{s}$, must not exceed a limiting value (and it is assumed that it is just reached there). The model can be stated in terms of lumped parameters characterizing each important phenomenon, which are easily understood in terms of heat transfer mechanisms. Four temperatures represent the thermal state of the system at that point, namely $T_{s}, T_{f}, T_{w}$ and $T_{e}$. Heat transfer mechanisms to be taken into account in the balance are characterized by:

$U_{f}=$ transmission coefficient from the tubes' outer surface to the heat carrier fluid, usually dominated by the convection coefficient inside the tubes. It is related to a transmission surface $A_{f}$.

$U_{w}=$ integrated convection coefficient from the tubes' outer surface to the window, applied to a surface $A_{w}$. Its value will depend a lot on the inner conditions in the receiver container. $U_{w}$

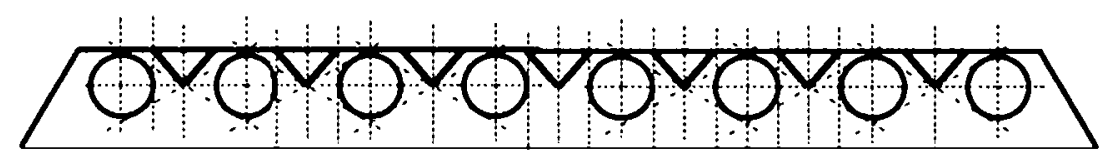

Fig. 2. Cross section of a multi-tube receiver, with 8 tubes and a wedge-type secondary reflector. 


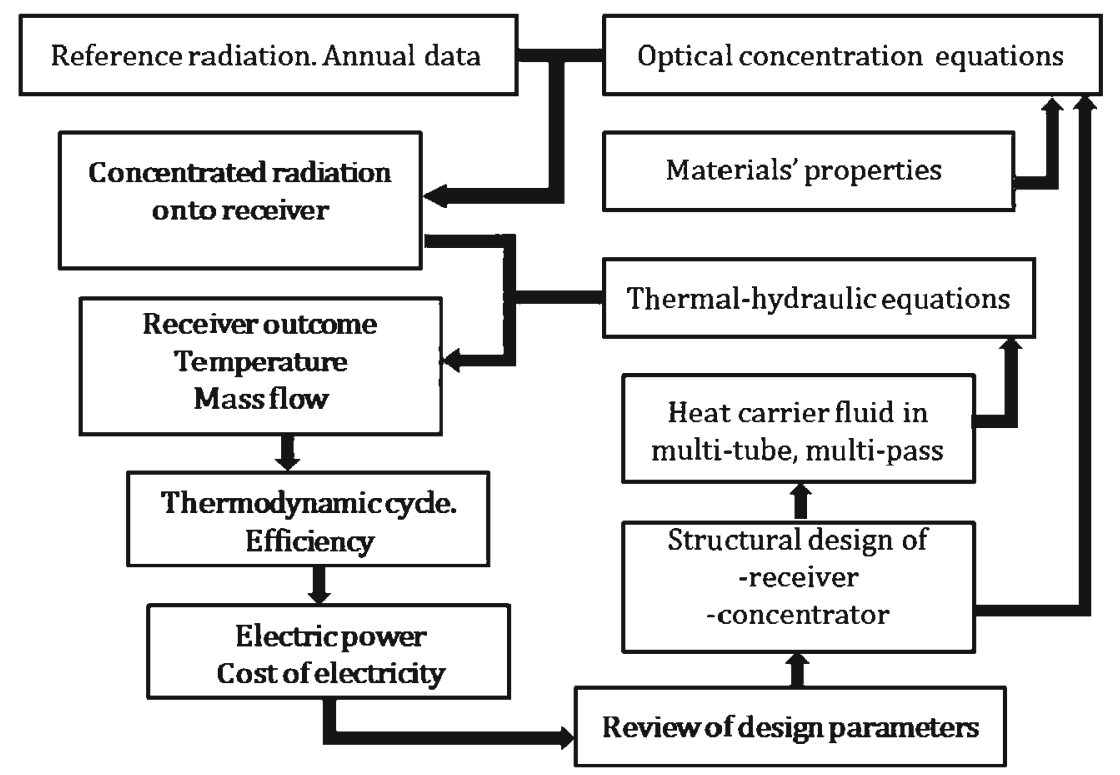

Fig. 3. Physical and computational methodology of the work.

will be very low (lower than $5 \mathrm{~W} / \mathrm{m}^{2} \mathrm{~K}$ ) in evacuated containers, and much bigger than that value, in hermetic containers filled with gas at atmospheric pressure (around $20 \mathrm{~W} / \mathrm{m}^{2} \mathrm{~K}$ ).

$U_{e}=$ integrated convection coefficient from the window outer surface to the environment

$\varepsilon_{5}=$ the effective emissivity in the radiation connection between the tube surface and the window, which is strongly dependent on the surface coating. A good coating can reach emissivity values around 0.1 while an ordinary painting to withstand high temperatures can have an emissivity value of 0.4 .

Finally, the window is connected thermally to the environment by convection, characterized by $U_{e}$ and by radiation, with an emissivity $\varepsilon_{w}$.

The balance can be written considering an impinging radiation flux $Q_{t}$ on a surface $A_{s}$.

$Q_{t} \cdot A_{s}=U_{f} \cdot A_{f} \cdot\left(T_{s}-T_{f}\right)+U_{w} \cdot A_{w} \cdot\left(T_{s}-T_{w}\right)$

$$
+A_{s} \cdot \varepsilon_{s} \cdot \sigma \cdot\left(T_{s}^{4}-T_{w}^{4}\right)
$$

A second balance closes the system

$$
\begin{aligned}
& U_{w} \cdot A_{w} \cdot\left(T_{s}-T_{w}\right)+A_{s} \cdot \varepsilon_{s} \cdot \sigma \cdot\left(T_{s}^{4}-T_{w}^{4}\right) \\
& =U_{e} \cdot A_{w} \cdot\left(T_{w}-T_{e}\right)+A_{w} \cdot \varepsilon_{w} \sigma \cdot\left(T_{w}^{4}-T_{e}^{4}\right)
\end{aligned}
$$

where $\sigma$ is the Stephan-Boltzmann constant, 5.67 $10^{-8} \mathrm{~W} /\left(\mathrm{K}^{4} \mathrm{~m}^{2}\right)$. In current coarse analysis we can consider all surfaces are equal (although a specific design could use cavity-type configurations for having $A_{w}$ values larger than $A_{f}$ ).

The former model is easily solved, and its result mainly depends on the values characterizing the thermal losses mechanisms inside the receiver container. For the sake of pointing out the main facts, two extreme cases can be considered: the isolated container, with a low emissivity surface coating and an evacuated inner atmosphere; and the cheap container, with a standard quality coating typical of coal-fired plants and an inner container atmosphere filled with an inert gas (or maybe air) at $0.1 \mathrm{MPa}$. They are identified by the labels Low and High losses.

Fig. 4 presents the energy and exergy efficiencies of the Low losses case as a function of the impinging radiation, for a surface temperature $T_{S}$ of $527^{\circ} \mathrm{C}$. The most relevant feature is the threshold shape of both curves, particularly for the exergy efficiency, which is

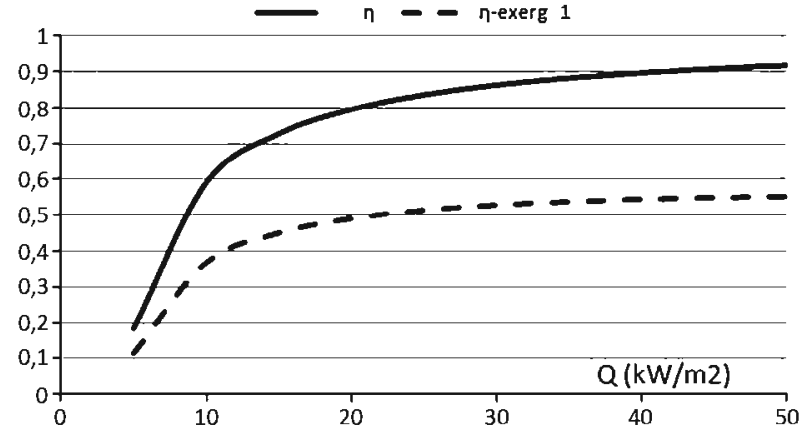

Fig. 4. Energy and exergy efficiencies of the Low losses case as a function of the impinging radiation, for a surface temperature $T_{s}$ of $527^{\circ} \mathrm{C}$.

calculated here as the energy efficiency times the Carnot efficiency for the fluid temperature. Such temperature depends on the $U_{f}$ coefficient, which is assumed to be $1 \mathrm{~kW} / \mathrm{m}^{2} \mathrm{~K}$ in this simulation.

The behavior is very similar for the High losses case, but the numbers are obviously different because the coefficients of the inner transfer mechanisms are bigger and the energy balance change, see Fig. 5. The threshold in this case is softer and the saturation level of the exergy efficiency is reached at much higher intensity values than in the Low losses case (around $80 \mathrm{~kW} / \mathrm{m}^{2}$

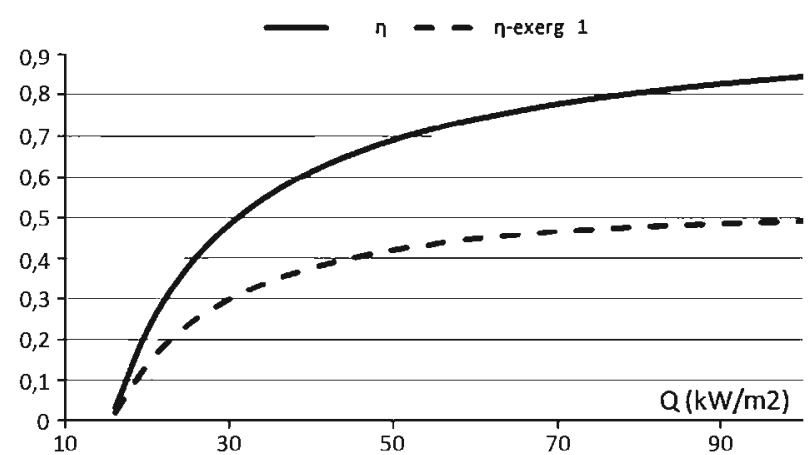

Fig. 5. Energy and exergy efficiencies of the High losses case as a function of the impinging radiation, for a surface temperature $T_{s}$ of $527^{\circ} \mathrm{C}$. 
instead $30 \mathrm{~kW} / \mathrm{m}^{2}$ ). This fact clearly points out that Fresnel concentrators, which are not efficient for reaching concentration factors above 50 , need high quality receivers in the sense of having a good surface coating and inhibited internal convection.

of course the former model is very limited because it works with lumped parameters. It has already been said that very accurate calculations can be done with numerical simulation codes, but it is very difficult to derive general guidelines from a number of specific cases. This is why it is advisable to identify the general trends with the close-to-physics model, and then calculate a number of cases accordingly.

The main general trend identified in our coarse analysis is that Low losses receivers (internal convection coefficient lower than $5 \mathrm{~W} / \mathrm{m}^{2} \mathrm{~K}$ and small emissivity, of the order of 0.1 ) yield very good performance with radiation intensities above $25 \mathrm{~kW} / \mathrm{m}^{2} \mathrm{~K}$. It is not needed to go to 3 or 4 times this value, but slightly above, as $40 \mathrm{~kW} / \mathrm{m}^{2} \mathrm{~K}$, which is something achievable with Fresnel concentrators. This is the second hint to reduce costs in solar thermal power plants.

\section{Fresnel reflector features in concentrating solar radiation; a comparison with parabolic trough collectors}

In the connection to the thermal problem of the receiver, the main magnitude is the intensity of the radiation impinging on its absorbing surface, which has been the main variable of our thermal simple model previously used to characterize the receiver. The linear integral of said intensity across the receiver is the linear power density, measured in $\mathrm{kW}$ per longitudinal linear meter of the receiver. While in parabolic trough collectors this value is close to $5 \mathrm{~kW} /$ $\mathrm{m}$, in Fresnel receivers it is between 10 and $15 \mathrm{~kW} / \mathrm{m}$. This fact obviously means a shorter total length in Fresnel receivers than in troughs for the same power, because the surface of mirrors associated to a meter of receiver is larger in Fresnel. However, it is slightly less effective than troughs in optical capture of original solar radiation, as will be shown now. In this section an analytical study of the useful energy impinging onto the field mirrors is first carried out, and then the results of a Monte Carlo Ray Tracing programs are given, PTCs being the reference in both studies.

\subsection{Analytic study of the specific energy reflected by the reflecting surface}

It is worth recalling that one-axis concentrators, also called linear concentrators, only concentrate the solar radiation components contained in the plane perpendicular to the rotating axis, which is fixed in the laboratory frame. The component along the axis obviously contributes to the definition of the real trajectories of the incoming and reflected rays, and have a strong influence in the so-called "end losses", caused by said axial component. Such longitudinal component is also negative in the sense that the distance traveled by the reflected ray is increased and, therefore, the beam is more spread when it impinges the receiver. Finally, the cosine factor is lower, which reduces the impinging energy per square meter of reflecting surface.

All calculations shown in this explanation are expressed in the plane perpendicular to the axis of the field, so-called the transversal plane. In particular, this is the case of the zenithal angle (angle formed by a ray from the Sun projected on said plane, and a vertical line in that plane).

In the numerical calculations presented afterwards, accurate values of the relevant coefficients will be used. For the introductory simplified model, mirrors' surface is assumed to be perfect, without inducing higher emittance in the sunbeams arriving from the Sun, which have a natural aperture of 9 miliradians.
The problem is therefore restricted to the geometric interaction of the solar radiation with the mirrors, which are tilted so that the reflected radiation impinges on the receiver. A PTC has the property of looking always to the Sun, and its aperture for capturing solar radiation is constant. This is so because the rotating structure includes both the concentrator and the receiver, which conveys more complex embodiments requiring rotating joints or flexible hoses in addition to a very heavy structure. On the contrary, a Fresnel array has independent structures for the concentrator and the receiver, and mirrors are chopped into stripes, where each one has a different tilt angle for focusing properly to the central point of the receiver. However, all mirrors rotate at the same speed, with different phases, if the mirrors are mounted correctly, in such a way that the axes of rotation coincide with a straight line (usually, the central one) on the surface of the mirror $[25,40,43,44]$. It must be said that this prescription is not met in some known designs of linear Fresnel reflectors, which introduces a decrease in the quality of the focusing on the receiver, but it is not a paramount effect for the problem under study.

The width of each mirror and the position of its center (axis) can be optimized for a given latitude, using the height of the receiver as the reference. An important value to characterize a mirror field is the filling factor, i.e., the ratio between the total surface of the mirrors to the total surface occupied by the mirror field. In NorthSouth embodiments the optimum value of this factor is in the range $0.65-0.75$. A higher factor conveys a very close position between neighboring mirrors, which produces sizeable interferences of shading and blocking. Detailed information on the geometry of the Fresnel array can be found in the literature $[25,39,31,44]$.

A first analytical exercise is the comparison between Fresnel and troughs in the first step of the energy chain, which is the interception of the solar radiation per surface unit of the mirrors. In a standard PTC with $5.76 \mathrm{~m}$ of aperture, the length of the parabola is $6.38 \mathrm{~m}$, i.e., 1.108 times longer. The total energy intercepted by the collector must be calculated as the percentage of the solar energy impinging onto a flat square meter that is always perpendicular to the sun beam, which is the Direct Normal Irradiance (DNI). If the DNI is assumed to be constant (equal to 1) along daytime (which is measured in terms of zenithal angle $\gamma$ in the transversal plane) and the sun path is assumed to be always in the transversal plane, such value holds: $\int_{-\pi / 2}^{+\pi / 2} d y=\pi$.

The energy impinging onto a PTC per reflecting surface square meter is, with an aperture of $5.76 \mathrm{~m}$ constant along the day:

$T=\frac{5.76 \int_{-\pi / 2}^{+\pi / 2} d \gamma}{6.38}=\frac{\pi}{1.108}$

Therefore, the interception effectiveness of the PTC reflecting surface would be: $t=0.9025$.

The aperture of a FA will depend on the Sun position in the plane normal to the rotating axis, and we need to integrate on zenithal angle $\gamma$, according to the geometry specified in Fig. 6. In general, the angle of incidence of the radiation in the left-hand-side mirror is $(\theta-\beta)$ and the angle for its symmetric mirror is $(\theta+\beta)$, where $\theta=\gamma / 2$.

The energy impinging onto a square meter of mirror along the day, $F$, can be calculated as the sum of energies impinging onto such mirror and onto its symmetric mirror at the other side of the receiver along half a day. Such value corresponds to

$$
\begin{aligned}
F= & \int_{0}^{\gamma_{*}}\left(\cos \left(\beta+\frac{\gamma}{2}\right)+\cos \left(\frac{\gamma}{2}-\beta\right)\right) d \gamma \\
F= & \int_{0}^{\gamma_{*}}\left(\cos (\beta) \cos \left(\frac{\gamma}{2}\right)-\sin (\beta) \sin \left(\frac{\gamma}{2}\right)+\cos (\beta) \cos \left(\frac{\gamma}{2}\right)\right. \\
& \left.+\sin (\beta) \sin \left(\frac{\gamma}{2}\right)\right) d \gamma
\end{aligned}
$$




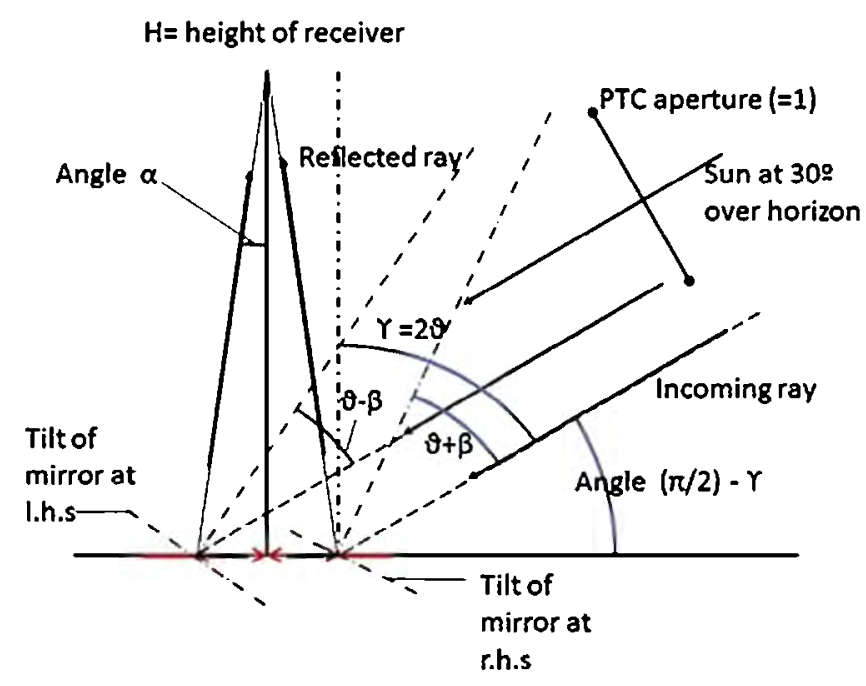

Fig. 6. The FA mirror field, represented by a pair of symmetric mirrors, in the general case of solar position.

$F=4 \cos (\beta) \sin \left(\frac{\gamma^{*}}{2}\right)$

For $\gamma^{*}=\pi / 2, F=4 \cdot \cos (\beta) \cdot \sin \left(\frac{\pi}{4}\right)=2.83 \cdot \cos (\beta)$. Therefore, the effectiveness of a FA mirror depending on its location is:

$f=\frac{2.83}{\pi} \cos \beta=0.90 \cos \beta$

Fig. 7 depicts the effectiveness of FA depending on the location of mirror in the transversal axis, measured as relative units compared to the height of the receiver. The value for a PTC, as well as the ratio $f / t$, is also given in such figure.

One may observe that the value of the ratio $f / t$ is always above 0.9 if the distance from the FA mirror to the receiver is shorter than the height of the latter. If the width of the FA mirror field is limited from -1 to +1 in units of said height, the average ratio of effectiveness $f / t$ will be 0.97 .

Thus, we might conclude that the effectiveness in the use of mirrors is approximately the same for FA and PTC if we do not consider the longitudinal component of the impinging radiation (the Sun was assumed to be in the normal plane, before). However, such component plays a very important role in the actual results,

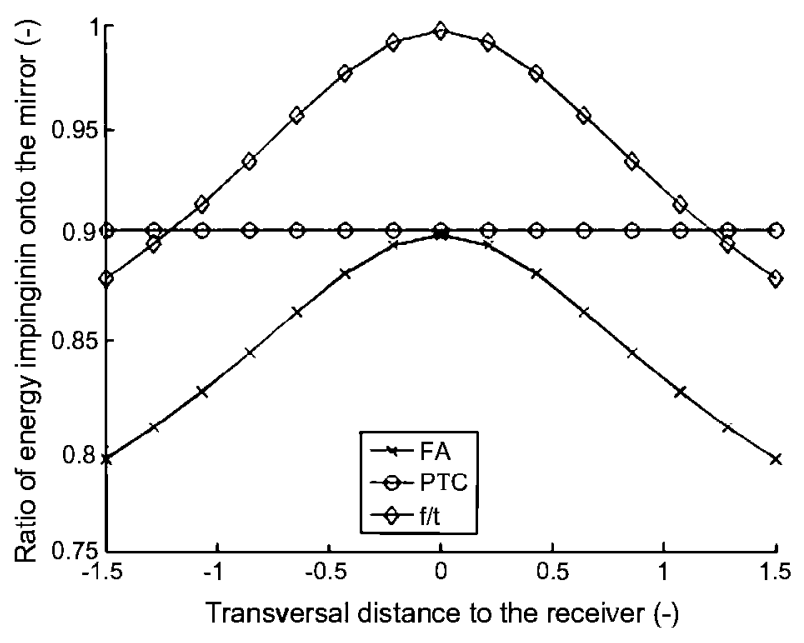

Fig. 7. Effectiveness of the reflecting surface for FA and PTC, as well as the ratio between such values, depending on the location of the mirror in a FA. DNI is assumed to be constant. depending on the geographical position, as will be seen for two sites, in Spain and Egypt.

In addition, the DNI along the day is assumed to follow the Rigollier model [45]. For each instant of the year when the estimated DNI is above $600 \mathrm{~W} / \mathrm{m}^{2}$ the direction of the impinging radiation, and thus the orientation of the mirrors, are obtained. Such energy is weighted with the clear sky probability for the chosen locations. Results of reflecting surface effectiveness are given in Fig. 8 for the cases of Almería and Aswan.

One may observe in Fig. 8 that the longitudinal component of the impinging radiation affects more importantly to FAs than to PTCs. The reason comes from the total actual aperture of the FA, which is maximum at noon and decreases when the Sun altitude diminishes, while it is constant in a PTC. At noon the longitudinal component of the impinging radiation gets its daily maximum and thus FAs decrease the effectiveness of the reflecting surface more importantly. The foregoing argument also explains why the difference between PTC and FA diminishes in Aswan, where the latitude is lower than in Almería and thus, the average daily maximum of longitudinal component is smaller.

The mean values of the PTC and FA reflecting surface effectiveness are given in Table 1. For FA such mean value depend on the width of the field, which is chosen 2 and 3 relative units (receiver height equal 1 ).

In this analysis, problems stemming from shading and blocking in FA have not been addressed, but they are actually marginal in well-designed mirrors arrays, with pitch between consecutive mirrors around 1.4 times the mirror width. PTCs also suffer shading effects between neighboring collectors, but no blocking due to the fact that each collector has its own receiver.

For example, distance between two neighboring trough collectors is typically $20.12 \mathrm{~m}$ in Spain, i.e. the field has a filling factor $28 \%$. If this is the case, actual energy impinging onto the collectors would be reduced by $2.9 \%$ in Almeria and $0.1 \%$ in Aswan. If the design requires a "compact" field, the distance between collectors could be reduced to $18 \mathrm{~m}$, i.e. filling factor of $32 \%$. Such field would reduce the useful energy by $4.3 \%$ in Almería and $0.3 \%$ in Aswan.

In FAs both shading and blocking processes are present. Shading effects occur when the Sun altitude is low, and thus one mirror is under the shade of the neighboring mirror. On the contrary, blocking process occurs with medium altitudes, when the radiation reflected in a mirror towards the receiver is first intercepted by the neighboring mirror. This process is typically present in mirrors far from the receiver. Fig. 9 shows the percentage of the mirror that is under the shadow or blocked by the neighboring mirror, assuming the width of mirrors and shift between them are the same as in the Fresdemo prototype.

One may observe that blocking is only present in the extreme mirrors, but during longer time than shading. The important factor for this study is the percentage of energy that is lost along the year due to both shading and blocking effects. A study has been carried out assuming locations in Almería and Aswan. In such study, two possible FA configurations are used:

- Fresdemo prototype, with 25 mirrors, a relative total width of 2.63 and a filling factor of $71.4 \%$.

- Puerto Errado commercial plant, with 16 mirrors, field width of 2.24 relative units and filling factor of $69.2 \%$.

Fig. 10 depicts the energy lost expressed as the percentage of the impinging radiation onto each mirror along the year.

One may observe that, if the field is not very wide, there are no blocking effects no matter where the field is located. In addition, shading factors vary by one percentage point in average when the filling factor changes from $69 \%$ to $71 \%$, which is an important change. 

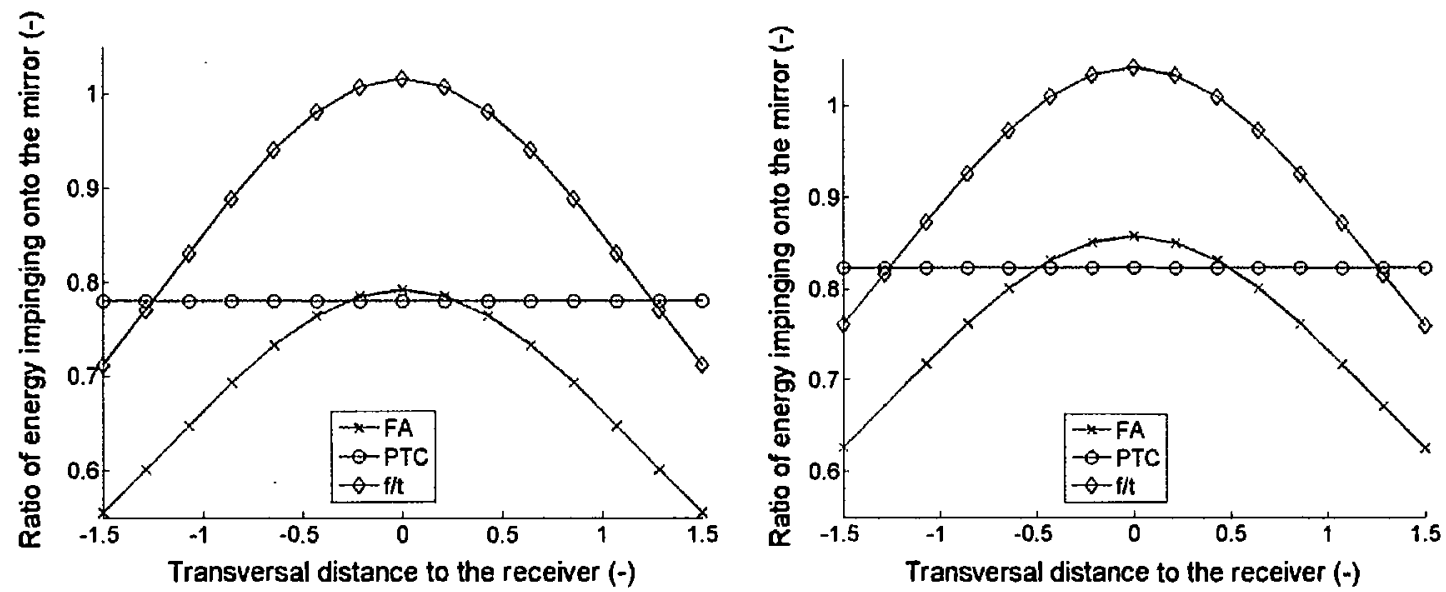

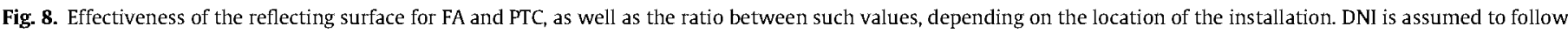
the Rigollier model for the cases of Almetia (left) and Aswan (right).

Table 1

Mean values of reflecting surface effectiveness for FA and PTC in different locations.

\begin{tabular}{|c|c|c|c|c|c|}
\hline Location & $t$ & $f($ width $=2)$ & t/f $($ width $=2)$ & $f($ width $=3)$ & $t / f($ width $=3)$ \\
\hline Almetía & 0.7796 & 0.7450 & 0.9556 & 0.6991 & 0.8967 \\
\hline Aswan & 0.8230 & 0.8110 & 0.9854 & 0.7661 & 0.9309 \\
\hline
\end{tabular}
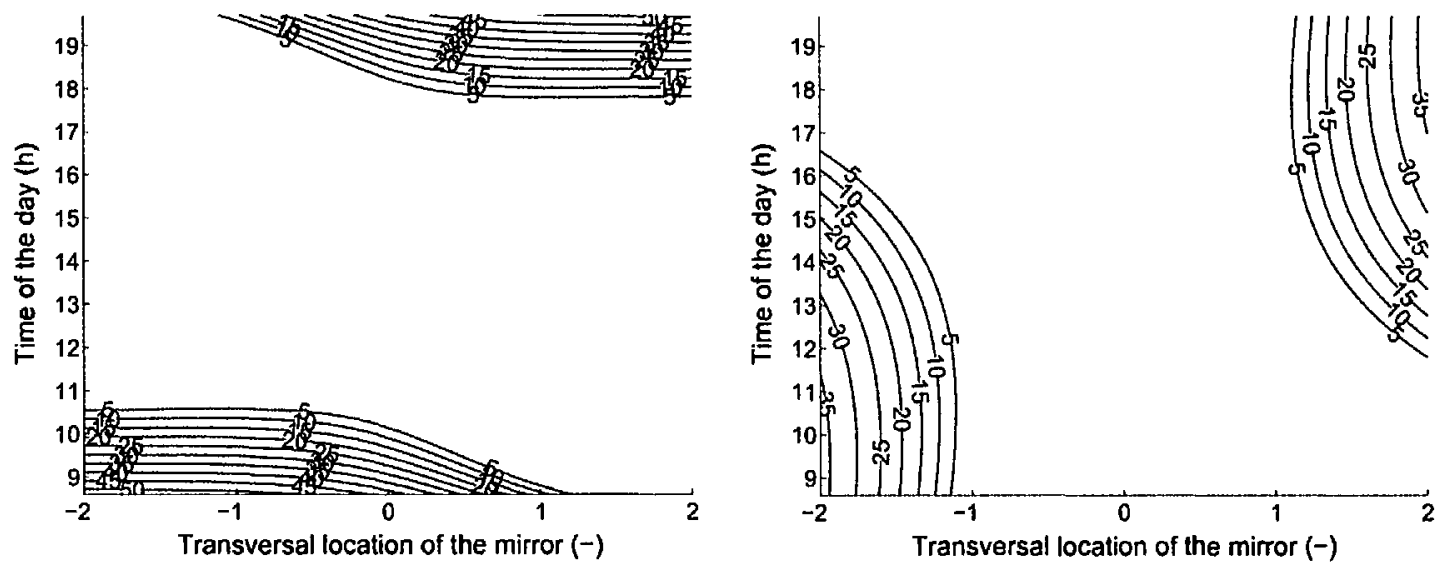

Fig. 9. Percentage of the mirror surface that suffers shading (left) and blocking (right) in a FA with Fresdemo configuration along a summer day in Almería.

Comparing these results with previous values given for PTCs, one may conclude that shading and blocking effects imply an extra loss of around $3-4 \%$ of the impinging radiation to Fresnel fields, which is not very important if it is considered that the filling factor is more than double. In addition, it must be taken into account that calculations were carried out for two existing prototypes, but those designs can be improved in the following optimization process. Even so, it can be stated that well designed Fresnel arrays have practically the same intercepting efficiency as PTCs thanks to the effect of having longer radius of curvature. Of course the quality of the concentrated radiation cannot be the same, because FA produces a wider beam at the receiver, but this fact can be compensated with a suitable multi-tube receiver design.

\subsection{Radiation intensity distribution from Fresnel reflectors onto receiver surface}

A key block to characterize the Fresnel performance is the one of "Optics", which must take into account the radiation reflection properties of the mirrors and their geometrical distribution, the sun-tracking of the mirrors to the Sun, and the concentration properties on the receiver. It is worth recalling that there is a variety of Fresnel array lay-outs and embodiments, but a general hint for North-South configurations is that the optimum ratio between receiver height and solar field width for horizontal receivers is 0.5 or smaller, and the filling factor is around 0.7 [9,39]. This configuration implies high concentrations in summer, and low in winter.

East-West embodiments are better in that sense for mediumlow latitudes, as Spain, where maximum values of concentration could be the same along the year with a proper design. In such regions the longitudinal component for NS embodiments is very high in winter, which may drive to the stop of the field during long periods. In addition, EW orientation permits the use of very compact fields, with optimum filling factors close to 1 . It is worth noting that the longitudinal component of the impinging radiation with such configuration would be very important during the morning and afternoon, reducing the total energy impinging onto the mirrors along the year. This is especially important in low latitudes, where the longitudinal component in NS embodiments is 

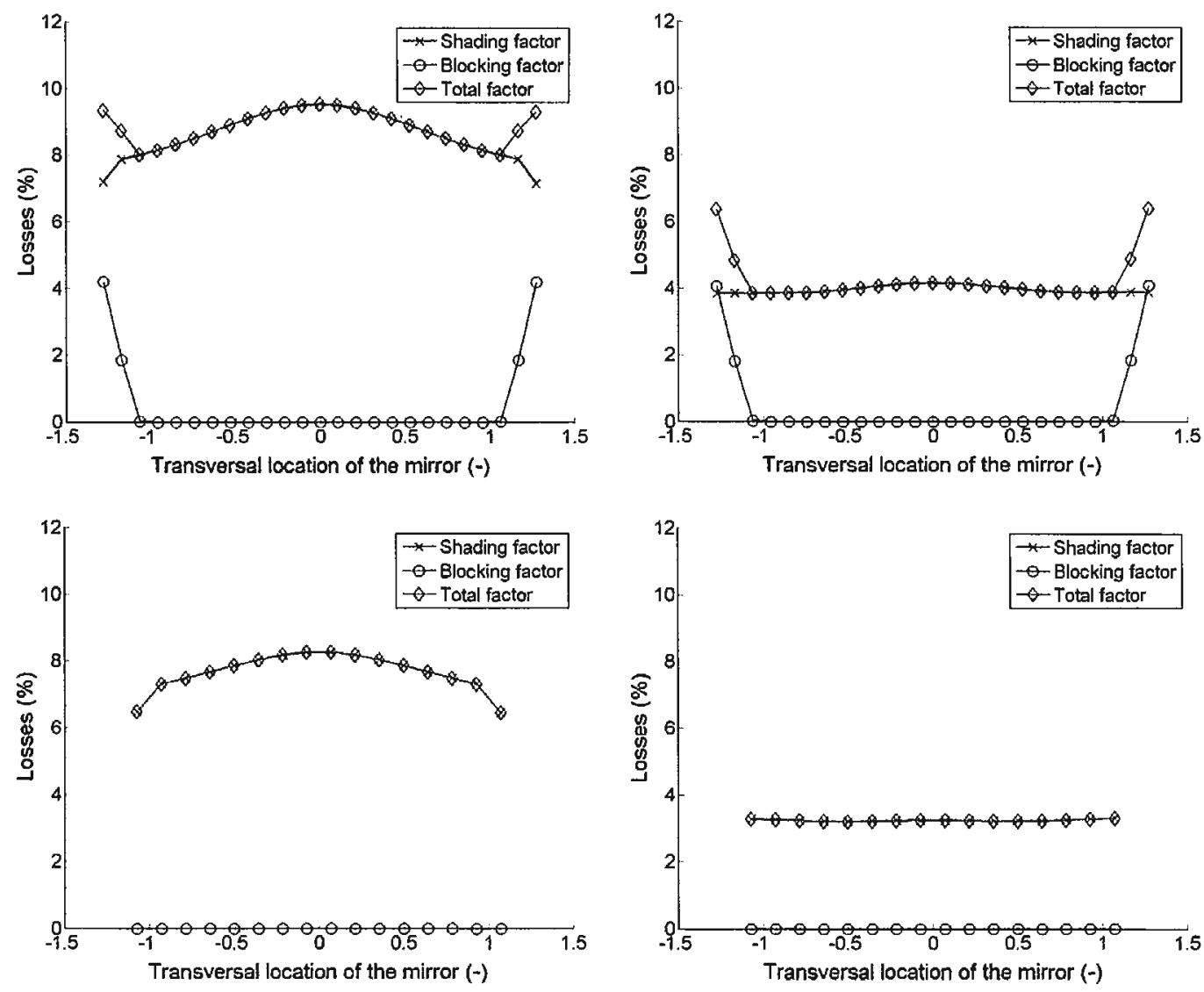

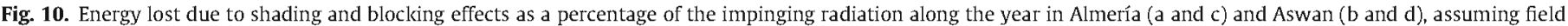
configuration of Fresdemo ( $a$ and $b$ ) and Puerto Errado ( $c$ and d).

very small at any time of the year (and this is the case for most of sunny places).

As a reference for analyzing the optical performance of the concentrator, we can use the concentrated radiation coming from a perfectly focused parabolic trough. Fig. 11 depicts the radiation intensity impinging onto the receiver, assuming it is flat and perpendicular to the Sun beam, during a spring day in Almería for a commercial PTC and a Fresnel field with the Fresdemo configuration. The width of the PTC collector is the diameter of commercial tube receivers, $7 \mathrm{~cm}$, while the receiver of the FA is around $30 \mathrm{~cm}$ wide. Results are given with a validated ray tracing model in Matlab, where 300,000 rays are sent every $6 \mathrm{~min}$. The Sun beam is

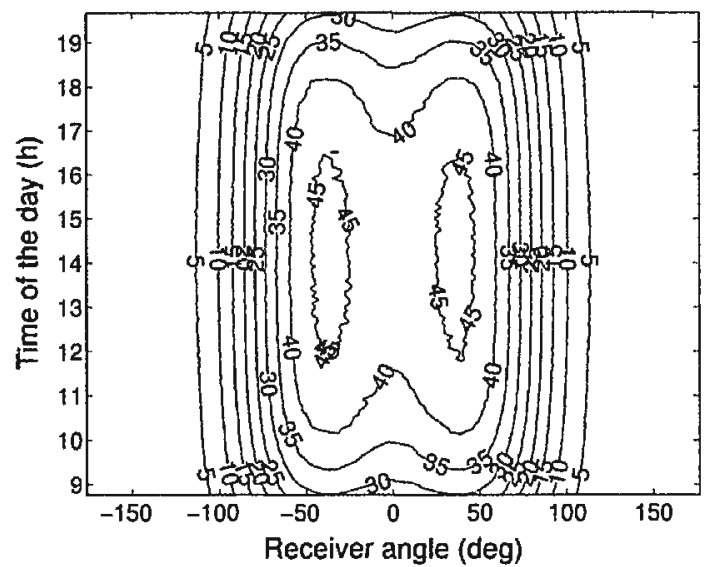

assumed to have Buie distribution, which is the one that better fits experimental data published by Lawrence Becker Laboratory and DLR [46], and the reflection on the mirrors produces an extra Gaussian error with a standard deviation of 5 milli-radian. Shading and blocking effects are considered in the FA case, but not in the PTC, as collectors are more spaced. Flux intensity is measured in the surface of the tube for a PTC and on a flat surface for FAs; therefore, in order to make a fair comparison the flux of PTCs should be multiplied by $\Pi$.

At first glance one may conclude that PTCs achieve much higher radiation intensities $\left(90 \mathrm{~kW} / \mathrm{m}^{2}\right.$ vs. $\left.55 \mathrm{~kW} / \mathrm{m}^{2}\right)$. Therefore, the receiver should be designed to obtain higher $\mathrm{HCF}$ temperatures

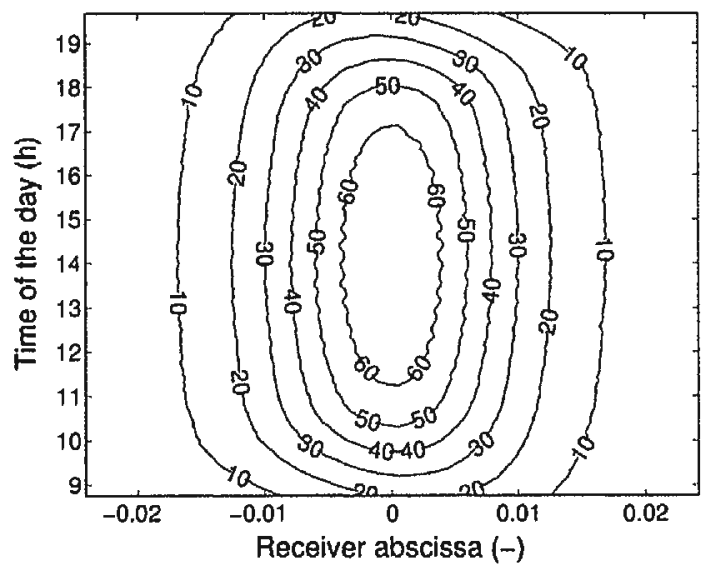

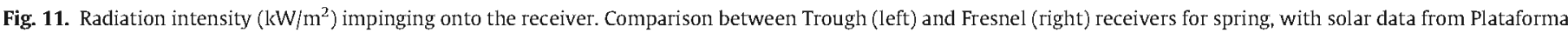
Solar De Almería. 


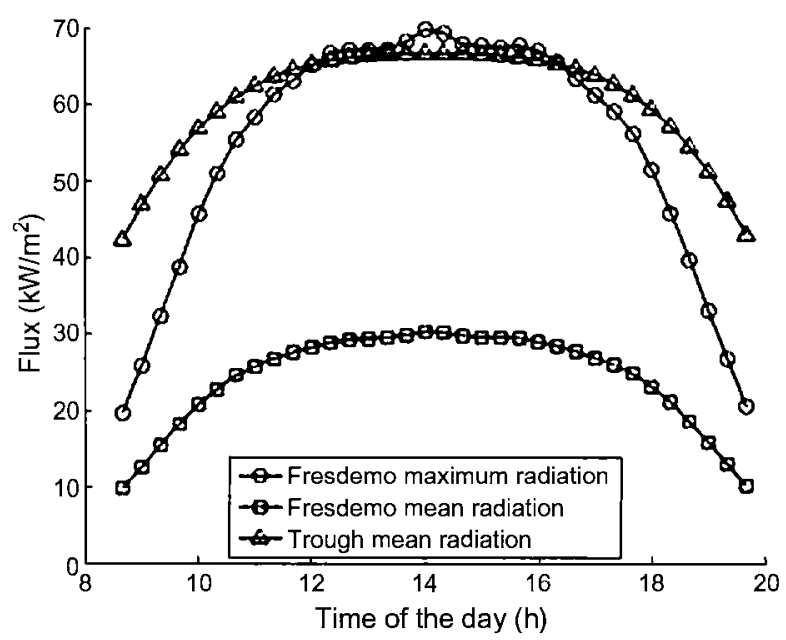

Fig. 12. Comparison between Trough and Fresnel receivers in summer, PSA Almería solar data. Fresdemo means that the mirrors array follow the same geometry as the LFR built there (in the PSA).

with a better efficiency. This problem is solved with exergy-tuned multi-tube receivers $[8,9]$. Multi-tubes Fresnel receivers heat the HCF progressively from the lateral tubes to the central ones, with increasing radiation intensities, and thus the maximum temperature that may be achieved is given by the radiation intensity in the central tube.

It results from the foregoing argument that we should compare the radiation intensity in the central part of the FA receiver with the mean radiation intensity in the PTC receiver. Such values, in addition to the mean radiation intensity in a FA, are given in Fig. 12 for the case previously depicted during a summer day.

One may observe that the mean radiation intensity in the Fresnel receiver is lower than half the mean intensity in the trough receiver. However, during most of the daytime (when both collectors receive a constant mean intensity) the radiation intensity in the central tubes of the Fresnel receiver is higher than the average in the trough tube. Therefore, maximum temperatures achievable can the same, and with a similar efficiency, in both cases.

Another data derived from Fig. 12 is that the lineal power intensity of the radiation impinging onto the receiver is higher for Fresnel arrays. This is consequence of the higher mirror surface used in such field, with a width of $15 \mathrm{~m}$ compared to $6.38 \mathrm{~m}$ in troughs. Mean radiation intensities are much higher in the PTC than in the $\mathrm{FA}\left(55 \mathrm{~kW} / \mathrm{m}^{2}\right.$ and $25 \mathrm{~kW} / \mathrm{m}^{2}$ respectively), but the width of the receivers is also different $(7 \mathrm{~cm}$ and $30 \mathrm{~cm})$. Therefore, lineal power intensity in PTCs in summer is around $3.85 \mathrm{~kW} / \mathrm{m}$, while in FAs is $7.5 \mathrm{~kW} / \mathrm{m}$. In addition, it must be taken into account that the transversal size of PTCs has already been optimized, and larger collectors would increase importantly the size of the structure. On the contrary, FAs are light structures than can be made larger, thus increasing the lineal power intensity and very likely reducing costs.

\section{Linear receivers and heat carrier fluids}

The linear receiver concept corresponds to a tube or bundle of tubes contained in an elongated box with a transparent window. The box can be:

\footnotetext{
- open to air circulation, which conveys very low insulation quality,

- almost hermetic, with inner pressure close to atmospheric one,

- totally hermetic and evacuated, which implies the best insulation quality.
}

The receiver equations are:

- the enthalpy balance, integrated along the receiver's length;

- the thermal transfer equation, already introduced in Section 3;

- and the fluid flow equation, which is mainly governed by the pressure gradient created in the circuit by a pump or a compressor.

There are a number of computer codes for solving these equations applied to specific cases with great detail $[8,13,47-49]$ and a couple of examples are given here to illustrate the thermal behavior of linear receivers under certain operation and boundary conditions. What matters in this context is to identify the features and trends of linear receivers operating in relevant conditions for getting the highest achievable exergy value in the HCF, which can be solved by minimizing entropy generation in the thermal interaction inside the receiver. The solution to this problem is based on a progressive capture of the radiation intensity, from outer to innermost stripes of the receiver, which in this case is not a single tube, but a bunch of parallel tubes (see Fig. 2) with chosen diameter, to establish the required fluid mechanics regime, and therefore the convection regime which transfers the radiation heat into the HCF.

In the case of single tubes, the only degrees of freedom are the diameter and length of the tube, which are not independent, because they are connected by the governing equations. However, those equations are self-consistent and some of the coefficients depend on the results, which make iterations necessary.

In the case of various tubes, the number of degrees of freedom increases, and the trajectories of the fluid inside the tubes, going forth and back inside the container [43], is a good tool to minimize exergy losses and to accommodate tubes dilatation within the container. Moreover, the multi-tube configuration also presents the advantage of reducing quite a lot the length of the collector module. This fact is related to the ratio $L / D, L$ standing for length and $D$ for tube diameter. Note that the actual linear power density in a tube is the receiver linear power density divided by the number of tubes (in average). This is a tool which can be used for increasing the convection coefficient, although it has the drawback of increasing the pressure loss, as will be seen later on. Before that, a comparison has been carried out on a single tube receiver to characterize several Heat Carrier Fluids. In such model it was assumed the tube to have an inner diameter of $6.5 \mathrm{~cm}$, to be $100 \mathrm{~m}$ long, and with an inner surface roughness of 60 microns. The power carried by the fluid is $350 \mathrm{~kW}$.

The comparison was made with the following fluids: $\mathrm{CO}_{2}$, (at two different pressures), a molten salt (Hitec), water/seam, and a molten eutectic made of lead and bismuth ( $\mathrm{PbBe}$ ). Results are given in Table 2 with the following conditions:

\footnotetext{
- Inlet temperature (except for water $/$ steam) $=250^{\circ} \mathrm{C}$.

- Outlet $\mathrm{T}$ (except for water $/$ steam $)=400^{\circ} \mathrm{C}$.

- Steam title, entrance to exit $=0.10$ to 0.20 .
}

It is worth commenting on the results of this exercise characterizing the cooling and mechanical properties of these coolants. Molten metal ( $\mathrm{PbBe}$ ) and boiling water have the highest convection coefficient, but they also present important drawbacks in other aspects of the plant. In particular, steam cannot be stored easily. In fact, the best storage media [50-58] seems to be molten salts, but pressurized water reacts very strongly with molten salts if a small accidental contact happens. Molten metal can be stored as such, but corrosion and chemical compatibility are main questions in this case, as pointed out in experimental programs of the nuclear industry. Molten salts have the risk of freezing, which seems 
Table 2

Comparison of heat carrier fluids for a reference case.

\begin{tabular}{|c|c|c|c|c|c|c|}
\hline & Therminol VP1 & $\mathrm{CO}_{2} 50$ bar & $\mathrm{CO}_{2} 100 \mathrm{bar}$ & Hitec XL & Water/Steam (311 $\mathrm{C})$ & Lead-Bi e. \\
\hline Mass flow $(\mathrm{kg} / \mathrm{s})$ & 0.98 & 2.09 & 2.02 & 1.62 & 1.02 & 16.06 \\
\hline Speed at entrance $(\mathrm{m} / \mathrm{s})$ & 0.36 & 12.71 & 5.99 & 0.25 & 0.40 & 0.49 \\
\hline Convection coeff. ( $\left.\mathrm{W} / \mathrm{m}^{2} \mathrm{C}\right)$ & 870 & 2050 & 2034 & 565 & 5976 & 4824 \\
\hline Pressure drop in $100 \mathrm{~m}$ (bar) & 0.021 & 1.514 & 0.699 & 0.038 & 0.093 & 0.414 \\
\hline Pumping power (W) & 3 & 6092 & 1324 & 3 & 12 & 65 \\
\hline
\end{tabular}

avoidable in insulated tanks, but it is actually riskier in the receiver tubes. Oil has a modest convective coefficient, but the risk of freezing is very small, and the required pumping power is also low. It has however, a low maximum allowable value in temperature and a high risk of fire, and it is not used as thermal energy storage because of the fire happened at SEGS-1 plant in California. An intermediate heat exchanger is currently used to transfer heat to the molten salt used for storage, but it can be recalled that an accidental contact between both fluids can produce a strong outburst and can set fire in the oil circuit. Last but not least, $\mathrm{CO}_{2}$ has the drawback (as any gas) of requiring very high pumping power, although its value decreases as pressure increases. For an ideal gas (which is not the case for $\mathrm{CO}_{2}$ ) pumping power decreases with pressure squared. So, increasing pressure a factor 2 conveys a power reduction by 4 [34]. In the example of Table 2, going up from 50 to 100 bar in pressure produces a decrease in pumping power from $6 \mathrm{~kW}$ to 1.32 . The latter represents $0.4 \%$ of the thermal energy carried by the coolant, which is a perfectly acceptable value for a power plant. Of course, another drawback of gases is that they can escape from the tubes through discontinuities such as the rotating joints of troughs, which happened in the PTC pilot plant in PSA (Almeria, Spain) [33,34]. It goes without saying that an inert gas as $\mathrm{CO}_{2}$ does not react chemically with molten salt in a violent way, and compact intermediate heat exchangers can be used for feeding the thermal energy storage.

It seems that all drawbacks of $\mathrm{CO}_{2}$ as $\mathrm{HCF}$ can be overcome, and there is an important feature that must be profited, namely, the possibility of reaching higher temperatures than the limitation of synthetic oil, which is around $390^{\circ} \mathrm{C}$ for Therminol VP1 [13,59]. However, with similar tubes and coatings, which withstand up to $500^{\circ} \mathrm{C}, \mathrm{CO}_{2}$ can attain $480^{\circ} \mathrm{C}$ [34]. The maximum temperatures of the steam generated from the heat of a given solar field can be estimated in $370^{\circ} \mathrm{C}$ for oil and $470^{\circ} \mathrm{C}$ for gas; which convey Rankine cycle efficiencies of $36.5 \%$ and $40.5 \%$, which is an additional advantage for cost/performance reduction. Note that a higher efficiency implies a smaller solar field, for the same electric power. of course, pumping power consumption must be subtracted from the former gross efficiency, but even so it can be estimated that a given power plant with a solar field of PTC with oil would require a solar field $10 \%$ larger than the same electric generator with a FresnelAdvanced solar field with $\mathrm{CO}_{2}$.

Figs. 13 and 14 show some relevant information about $\mathrm{CO}_{2}$ as heat carrier fluid. in the former, the effect of increasing the tube diameter is very strong for reducing pumping power, but at the same time it has very negative impact on the tube temperature, because the temperature jump from it to the fluid increases a lot. Fig. 14 depicts the output of a simulation, where it has been assume that the tube is of type NPS2 Sch. 80 , which corresponds to an inner diameter $49.26 \mathrm{~mm}$, and the inlet pressure of the gas is $10 \mathrm{MPa}$. Series $1-4$ correspond to mass flows of $0.6 \mathrm{~kg} / \mathrm{s}$, $0.8 \mathrm{~kg} / \mathrm{s}, 1.0 \mathrm{~kg} / \mathrm{s}$ and $1.4 \mathrm{~kg} / \mathrm{s}$. The efficiency in transferring the impinging radiation to the HCF is depicted as a function of the outlet temperature, for different working conditions of the cooling gas. It can be seen that efficiency decreases as the HCF temperature increases, but a gas temperature of $475^{\circ} \mathrm{C}$ is achievable with an efficiency of $80 \%$ (with the highest gas flow rate; series 4 ). It is

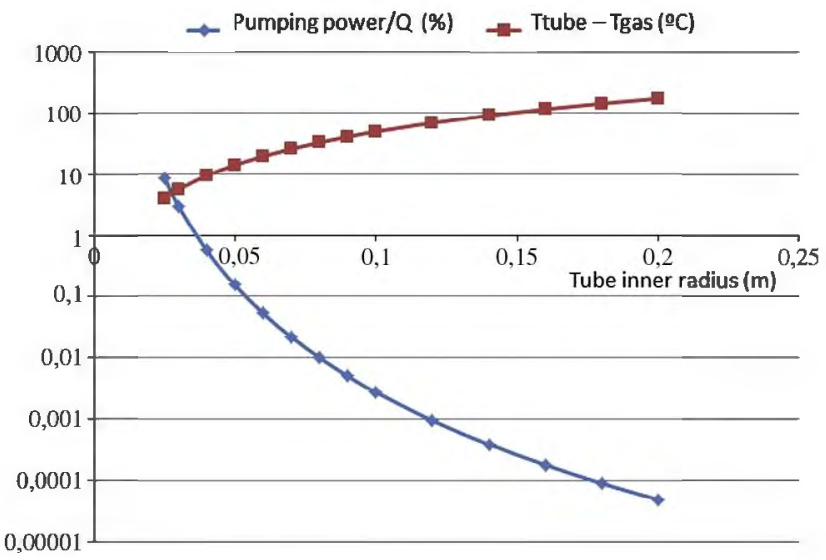

Fig. 13. Pumping power for $\mathrm{CO}_{2}$ at 100 bar vs. internal diameter of the tube and temperature difference between the tube inner surface and the fluid. Fluid mass flow (in $\mathrm{kg} / \mathrm{s}$ ) and thermal transfer area ( $\mathrm{DDL}$ ) are kept constant in this case.

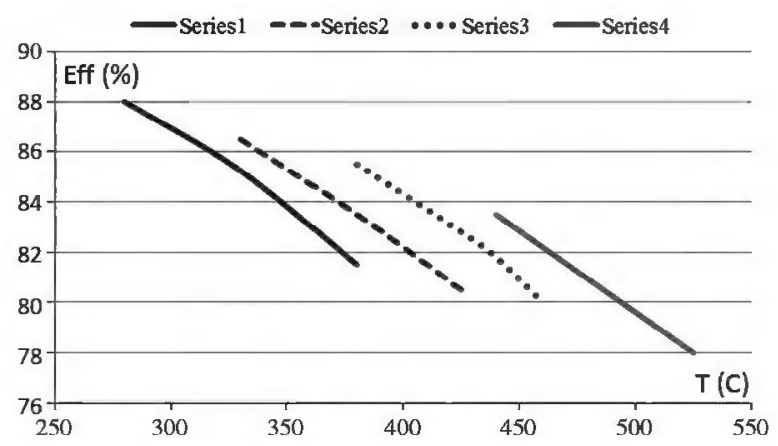

Fig. 14. Thermal efficiency in capturing energy in a Fresnel receiver vs exit $T$ of gas for inlet temperatures varying from $160^{\circ} \mathrm{C}$ (maximum efficiency of the series) to $270^{\circ} \mathrm{C}$

worth pointing out that a wrong selection of the gas flow rate would reduce enormously the receiver thermal efficiency.

\section{Solar field layout and plant size}

A solar thermal power plant is typically made of a central power block surrounded by the Solar Field (SF) which has a modular structure, where the unitary module is the lattice cell of the system. Although the plant pumping power and the overall performance will also depend on the overall geometry, the lattice module contains the main elements of the SF and represents a very high percentage of the cost.

The methodology followed in this work is to identify an optimized design of the module according to the principles of the Optical and Thermal analysis. This task implies to select specifications for each of the components of the energy transmission chain according to the qualitative analysis guiding each of the chain steps, and carrying out detailed calculations for properly 
characterizing a given design. The final integration into a plant will be used as an assessment for reconsidering any of the options chosen, which eventually can be modified for having better fitting with the connecting links of the energy transmission chain. Once the module and the plant designs are finalized, we must make the structural analysis and the economic study for calculating the cost of the plant. The objective is to keep the design very close to the optimum optical and thermal state, with the minimum cost, which is usually oriented by the minimum complexity and the minimum amount of material needed to build it.

In the plant integration process, a fundamental specification is the nominal power of the thermodynamic cycle, which also has a strong influence on the cost. Another important specification relates to Thermal Energy Storage (TES). At current time molten salts are the main technology to store solar thermal energy. This is normally done with to big containers, one with hot salts and the other with relatively cold salts, which often drive to corrosion issues [60]. Alternative solutions may be found in the literature, such as a double level thermal storage [61] and thermocline storage one only container $[62,63]$. In addition, important efforts are being made at current time in order to find molten salts with lower minimum temperatures [64]: it has been observed in previous figures that the thermal efficiency of the receiver decreases as the inlet temperature increases; thus, the minimum storage temperatures should be reduced in order to increase thermal efficiency.

A decision must be made about including or not TES in the plant, and a second decision is about the size of the TES, which in turn has an influence on the size of the Solar Field. It must be recalled that the larger the TES the larger the SF. This is usually defined by the so called Solar Multiple, which is the ratio of the actual SF size to the size needed to generate the thermal power to feed the power block in nominal conditions. For our current purpose, it is enough to know the nominal power and the SM value.

In our optical and thermal optimization, the final result is a module design as the one depicted in Fig. 15, including a mirror array with a half-width equal to the height of the receiver.

Mirrors are represented at $1.5 \mathrm{~m}$ over the ground, and the receiver is $10 \mathrm{~m}$ over the mirrors axes. The total length of the collector module is $100 \mathrm{~m}$, but it is split into two halves, and the tubes are inside a long box hanging from an upper double truss which is supported by 10 archs, or pillars. Nevertheless, those numbers must be reviewed in the structural analysis.

Another salient feature of Advanced Fresnel is that they can be placed in a very compact configuration, because the optical interference between parallel modules is rather small. The pitch between centerlines of FA collectors can be as small as 1.1 times the width of the collector field, while this value is around 4 in PTC plants. This is important not only for a smaller use of land, but for the shorter distances of the HCF from the collector to the central power block and back.
Such distances are especially dominant in pumping power losses, which increase more than linearly with the plant nominal power. On the contrary, the specific investment cost of the power block decreases dramatically with the nominal power, as shown in Table 3, which is an estimate on steam turbines in general, not only for solar thermal plants.

Currently built units are in the range of 50-300 MW. For instance, SEGS IX is a PTC plant with a nominal power of $80 \mathrm{MW}$ [65].

We will use that nominal power as a reference, and will use the former numbers we have identified for troughs and Fresnel plants, taking into account the difference in heat carrier fluid temperature and so forth.

For a PTC, according to the ratio obtained in former section, the thermal power required for the nominal case would be $264 \mathrm{MW}$; and presuming a linear power density of $4 \mathrm{~kW} / \mathrm{m}$, the total collectors' length would be $66 \mathrm{~km}$. We must include a Solar Multiple value, and we select $\mathrm{SM}=1.21$ without Thermal Energy Storage, so requiring a total length of $80 \mathrm{~km}$.

In a Fresnel Advanced power plant the nominal thermal power would be 3 times $80 \mathrm{MW}$, which gives $240 \mathrm{MW}$. Presuming a linear power density $9.5 \mathrm{~kW} / \mathrm{m}$, we need $25 \mathrm{~km}$ of collectors, with a mirror field width of $20 \mathrm{~m}$, and a filling factor of 0.7 , with a pitch of $22 \mathrm{~m}$ between parallel receivers. We must add the Solar Multiple effect to the previous numbers, and therefore the total collectors length would be $30 \mathrm{~km}$ for yielding 285 thermal MW (the collector width and pitch are not changed) and the total land use goes up to $660,000 \mathrm{~m}^{2}$, which can be accommodated in a square of $820 \mathrm{~m}$ side. The distance to be covered by the connecting pipes will be roughly proportional to that value, which is again an advantage for Fresnel arrays. It is also important to clarify that the mirror field is not fully covered with mirrors, but just a fraction of it (the so called filling factor) which is close to $70 \%$. If mirrors are $1 \mathrm{~m}$ wide (in average) there must be 14 lines of mirrors per receiver.

It is important to underline that the total collector length in PTC is 2.65 times as long as in FA fields. This is also of great importance for cost reduction. Moreover, FA seems to have fewer problems for going to high unitary power, which implies smaller specific cost in the power block. Moving from 50 to 100 MW represents a reduction from 400 US $\$ / \mathrm{kW}$ to 250 , which is a substantial change. The decrease in cost can be estimated in $60-65 \%$ when doubling power. Besides that, Fresnel modules can grow to higher receivers and

\section{Table 3}

First cost of the power block (turbine plus condenser; without including boilers and steam generators) vs. turbine nominal power. Specific cost also given $(€ / \mathrm{W})$.

\begin{tabular}{llllll}
\hline MW & 5 & 10 & 20 & 50 & 100 \\
\hline M $€$ & 5 & 7.5 & 10 & 20 & 25 \\
$€ / W$ & 1 & 0.75 & 0.5 & 0.4 & 0.25 \\
\hline
\end{tabular}

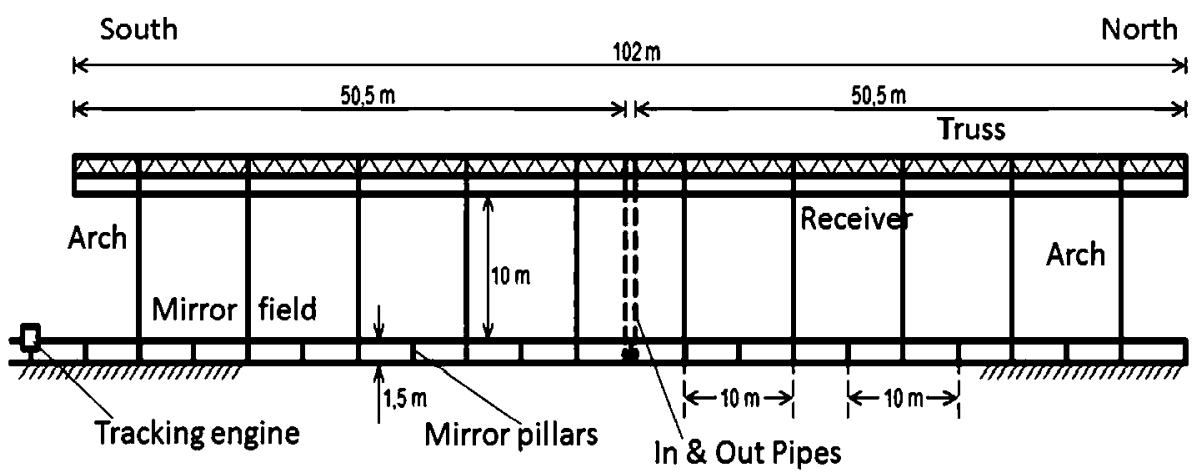

Fig. 15. Vertical outline of a prototype of advanced Fresnel array with multi-tube receiver (not to scale; see numbers). 
wider mirror fields, which is a subject still to be studied for reaching a better optimum in Fresnel performance.

A simple configuration of the FA plant is shown in Fig. 16, where each lattice cell is $100 \mathrm{~m}$ wide and $110 \mathrm{~m}$ long, and hosts $4 \mathrm{mod}-$ ules (unless one of the modules is removed for placing a decentralized TES).The central four cells are reserved for the central TES and the power block. Overall piping can be made from each lattice cell, either to the central block or to the auxiliary TES, because thermal energy storage is embodied in the plant at two levels, and they could be managed to satisfy both the external needs of the customer, and to minimized the cost of electricity by getting better operational results.

Last but not least, there is a tendency to disregard the use of land in solar thermal energy economics, and this is not wise, because most of the promoters have a limited size in the estate they can devote to build a power plant. In that case, FA offers the possibility to reach higher power, with the corresponding benefit in the power block cost.

\section{Solar field components and structures}

Structural analysis is also a fundamental part of the methodology, with two levels of tasks: the conceptual discussion for guiding the optimization process, and the accurate calculations once the design window has been properly narrowed. Before stating the analysis at the conceptual level, it must be pointed out that there are two independent bodies (concentrator and receiver) and each of them has two types of components:

- the essential parts (mirrors in the concentrator; tubes in the receiver)

- and the supporting parts.

Additionally, the supporting parts are composed of suspended bodies (beams, truss) and pillars. The goal in this section is to find the cheapest structure to hold the essential parts. Before making the economic estimate, including unitary prices of materials and so on, a mass accountancy will be made of all materials needed to make the full assembly.

In the concentrator, the mirrors are supposed to be $1 \mathrm{~m}$ wide and $0.2 \mathrm{~cm}$ thick, with a linear weigh of $50 \mathrm{~N} / \mathrm{m}$. Supporting transversal frames are obviously needed to fix the mirrors to the axial beam, but it is worth noting that the mirror glass is a stiff body (as an eggshell) and therefore the frames should not be heavy; thus a linear weigh of $10 \mathrm{~N} / \mathrm{m}$ is enough.

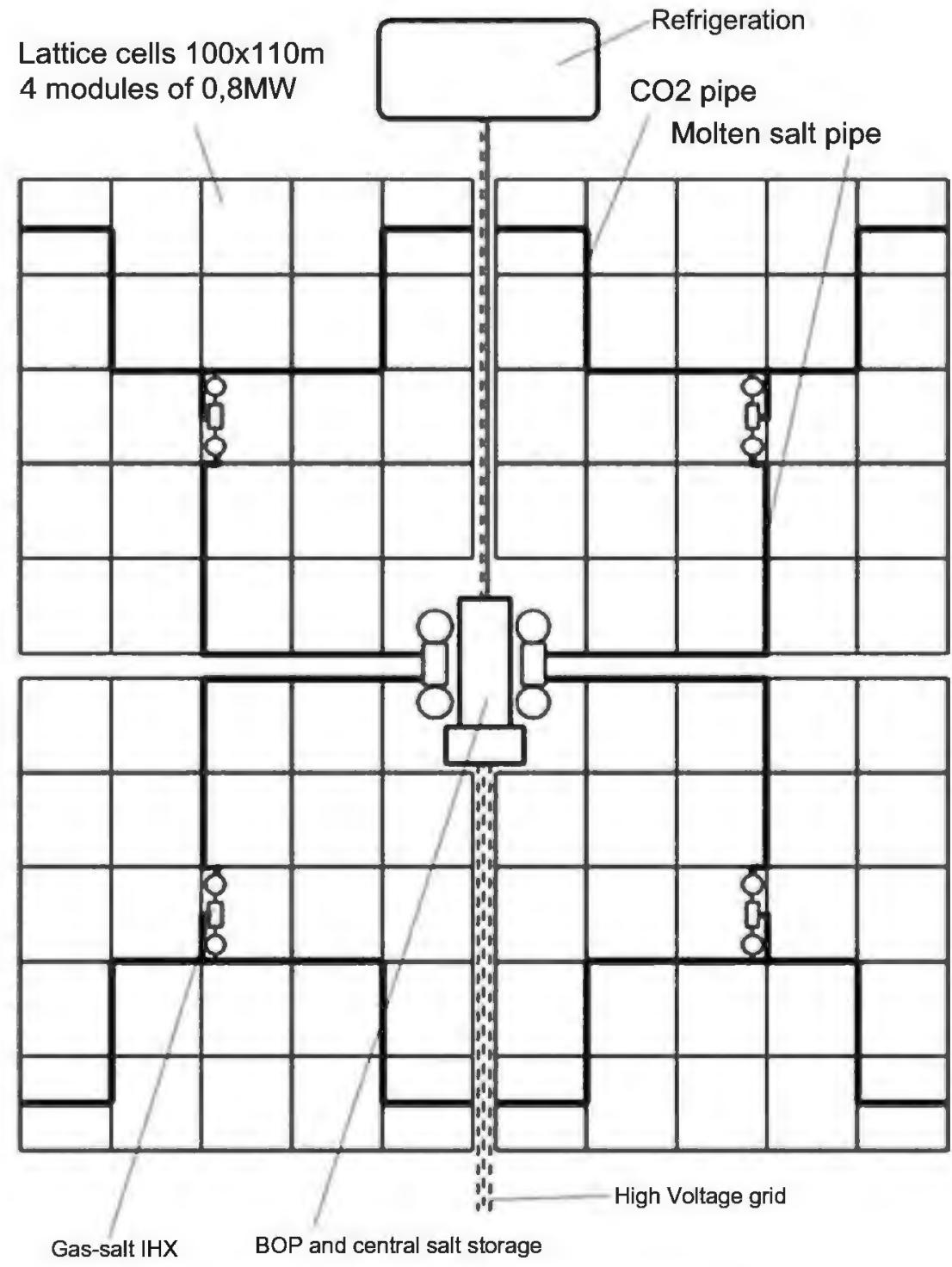

Fig. 16. A modular layout for the Fresnel-based power plant. 
The equation of the maximum deflection of a beam with fixed ends, supporting a total linear load $w(\mathrm{~N} / \mathrm{m})$, with a length $L$, a moment of inertia $I$ and an elastic modulus $E$, is

$f=w \cdot L^{4} / 384 \cdot E \cdot I$

$w=u+s$

where $u$ is the useful linear mass density (as the mass of mirrors and frames per unit length) and $s$ is the linear mass density of the supporting structures. It is worth noting that "s" behaves as $I^{1 / 2}$ once the shape of the structure is fixed.

As this deflection should be limited because of the stiffness needed in optical geometry for getting high radiation concentration values, this equation is a guide for defining the size of the supporting structures, and therefore their masses. If the beam is assumed to be a hollow prism with a square cross section of side " $b$ " and thickness " $t$ ", and the maximum deflection is limited to a value (for instance $f / L=0.002$ radians) the former equation can be solved with standard values of $b$ and $t$ for an overweight of $60 \mathrm{~N} / \mathrm{m}$. Note that a hollow prism has the following cross section surface $A$ and moment of inertia $I$

$A=4 \cdot b \cdot t-4 \cdot t^{2}$

$I=\left(6 \cdot b^{3} \cdot t-12 \cdot b^{2} \cdot t^{2}+8 \cdot b \cdot t^{3}\right) / 12+t(b-2 \cdot t)^{3} / 6$

The beam equation for a useful linear load $\mathbf{u}$, with a maximum deflection of 0.002 radians becomes

$9240 \cdot b^{2}+u=0.384 \cdot 0.0183 \cdot b^{4} \cdot 2,1: 10^{11} / L^{3}$

and the following linear weight of the beam is obtained ( $L$ must be in meters)

$Y_{b}(\mathrm{~N} / \mathrm{m})=1 \cdot L^{2}$

The optimum distance has to minimize the total value of the structural materials, including pillars. Note that the pillar weight typically has two components; a fixed term (independent on $L$ ) and a quadratic term (depending on $L^{2}$ ). When that weight is accounted for in terms of linear weigh, and standard values are chosen for the four legs of each pillar and the transversal rigidity plates, plus the foundation plate, the equation to be minimized is the total linear weight $Y$, which can be expressed as

$Y=p \cdot L^{2}+q \cdot L+r / L$

and the optimum value of $L$ is given by

$d Y / d L=0=2 \cdot p \cdot L+q-r / L^{2}$

For the mirror array already introduced, these coefficients have the following values: $p=1 \mathrm{~N} / \mathrm{m}^{3} ; q=2 \mathrm{~N} / \mathrm{m}^{2} ; r=300 \mathrm{~N}$; which gives the value $L=5 \mathrm{~m}$, which represents a linear weight of $25 \mathrm{~N} /$ $\mathrm{m}$ for the beam, and $70 \mathrm{~N} / \mathrm{m}$ for the pillars and stiffness structure (and it is worth recalling that the mirror and frame linear weight was fixed at $60 \mathrm{~N} / \mathrm{m}$ ). Of course, this is applied to each linear set of mirrors.

Similar calculations must be done for the receiver, although the pillar weight is almost independent on the distance between pillars, because it mainly depends on the receiver height, and can be estimated in $2200 \mathrm{~N}$. The linear weight of the supported components is much higher than that of a mirror line, and it depends on the specific structure of the bundle of tubes. A representative value is $600 \mathrm{~N} / \mathrm{m}$, including tubes $(400 \mathrm{~N} / \mathrm{m})$, glass $(50 \mathrm{~N} / \mathrm{m})$ and container $(150 \mathrm{~N} / \mathrm{m})$. The receiver is considered to hang from a couple of parallel beams, or a truss, which can deflect 0.005 radians (as design value) and has a linear weight of $100 \mathrm{~N} / \mathrm{m}$. The total linear weight of the receiver must include the pillars, which have a linear weight equal to the total weight divided by $L$. The unknown $Y$ is expressed as

$Y(\mathrm{~N} / \mathrm{m})=L^{2}+2200 / L$

which gives an optimum value $L=1100^{1 / 3} \mathrm{~m}$ (which is $L=10 \mathrm{~m}$ in round numbers). So the total linear weight of structural steel in the receiver is $320 \mathrm{~N} / \mathrm{m}$ plus 150 , which amounts to $470 \mathrm{~N} / \mathrm{m}$. Additionally, there are $400 \mathrm{~N} / \mathrm{m}$ of high quality steel (stainless steel) and $50 \mathrm{~N} / \mathrm{m}$ of glass.

We must now add the material accountancy from the mirror field, where we find 14 lines with $50 \mathrm{~N} / \mathrm{m}$ of glass per line plus $105 \mathrm{~N} / \mathrm{m}$ of structural steel, including frames. So, if measured in terms of receiver length, they amount to $700 \mathrm{~N} / \mathrm{m}$ of glass and $1470 \mathrm{~N} / \mathrm{m}$ of structural steel. Although more detailed differentiation among similar steels or similar glasses could be done in a specific project, the following values characterize the advanced Fresnel array with multi-tube receiver:

- Structural steel $1940 \mathrm{~N} / \mathrm{m}$.

- Stainless steel $400 \mathrm{~N} / \mathrm{m}$.

- Glass $750 \mathrm{~N} / \mathrm{m}$

As a reference, following masses are found in a 12-meter Parabolic Trough Collector

- Mirrors (glass) $600 \mathrm{~kg}$.

- Frames (structural steel) $500 \mathrm{~kg}$

- Torque box (structural steel) $640 \mathrm{~kg}$.

- Pillars (structural steel) $300 \mathrm{~kg}$.

- Tube (stainless steel) $50 \mathrm{~kg}$.

Which can be expressed per length unit of the receiver tube,

- Structural steel $1200 \mathrm{~N} / \mathrm{m}$.

- Stainless steel $45 \mathrm{~N} / \mathrm{m}$.

- Glass $500 \mathrm{~N} / \mathrm{m}$.

It must now be remembered that for the same electric generation capacity, Fresnel receiver length is shorter than the PTC receiver by a factor 2.65. In previous section it was calculated that a PTC plant of $80 \mathrm{MW}$-e (nominal) with a SM of 1.21 requires $80 \mathrm{~km}$ of collector, while a Fresnel plant would require $30 \mathrm{~km}$. This fact also has an impact on the concrete needed for the foundations of the structures of each plant. In the PTC case there will be 6600 foundations thick slabs, totalizing 13,200 tons. In the Fresnel plant there will be about 3000 mid-size foundations slabs amounting to 4000 tons and close to 60,000 minor slabs ( $25 \mathrm{~kg}$ each) amounting to 1500 tons, which means 5500 tons of concrete in the Fresnel plant. A coarse but comprehensive comparison is given in Table 4, where a qualification has been given with relative points depending on the cost of the material: Structural steel $=1 ;$ Stainless steel $=6$ for PTC evacuated tubes and 5 for tubes without individual glass envelope; Glass $=6$; Concrete $=0.5$, including civil work and assembly.

The outcome of this exercise is that Fresnel solar fields can capture the solar heat for generating a given level of power with a cost roughly estimated in $2 / 3$ of the cost of PTC plants.

Table 4

Comparison between PTF and Fresnel plants in the solar field).

\begin{tabular}{lrrrr}
\hline Material & PTC, tons & PTC, points & Fresnel, tons & Fresnel, points \\
\hline Structure steel & 6360 & 6360 & 3880 & 3880 \\
Stainless steel & 240 & 1440 & 800 & 4000 \\
Glass & 2650 & 15,900 & 1500 & 9000 \\
Concrete & 13,200 & 6600 & 5500 & 2750 \\
Total points & & 30,300 & & 19,630 \\
\hline
\end{tabular}




\section{Plant economic study and summary}

The Fresnel-based module we have introduced and defined is the basic unit of the plant solar field, which is a macro-structure where distances should be minimized. The proposal we presented is a square lattice layout, thermally feeding a BOP with a Rankine cycle. Steam can be generated either directly from the $\mathrm{CO}_{2}$ or in salt/water heat exchanger, although this alternative conveys higher risks because of accidental interactions between both substances.

Another important features that should be studied for any site suitable for solar applications is air-cooling, without water consumption, although it entails a reduction of $0.7 \%$ in efficiency (in absolute terms) induced by an increase in cooling temperature of $10^{\circ} \mathrm{C}$. This technology of dry-cooling refrigeration can be improved by storing "cooled water" chilled at night [66]. Indeed water consumption can be a very important operational cost, because in some sunny places it is much more expensive than energy.

Our cost estimates will mainly focus the investment or fixed cost, and will be based on unitary costs for standard industrial construction in Spain, except for the receiver tubes, which are very specific. It cannot be admitted that structural steel, which has a total cost (including assembly) of $5 € / \mathrm{kg}$ in general industrial applications, becomes more expensive just for the reason of being applied to solar thermal installations (see Table 5).

The plant will need 300 of these modules to have a total length of $30 \mathrm{~km}$, which makes a total solar field of $105 \mathrm{M} \epsilon$. The Power Block (BOP \& Electric equipment) must now be added, which can rated at $500 € / \mathrm{kW}$ (electric) so amounting to $40 \mathrm{M \epsilon}$. It must also be added a general account for the Land, Engineering, Permits, Taxes and so on, which can be estimated in $25 \mathrm{ME}$, which makes a total investment of $170 \mathrm{M} €$. This is a specific first cost of $2.15 € /$ $\mathrm{W}(\mathrm{e})$, which is a good target for solar thermal current development.

If the life of the plant is taken as 15 years (in present worth) the fixed cost would be $11.33 \mathrm{M} € /$ year; and presuming 2200 equivalent hours in the operation of the plat, the annual production would be $176,000 \mathrm{MW}$ h. So the specific fixed cost would be $65 € / \mathrm{MW} \mathrm{h}(6.5 \mathrm{c} € / \mathrm{kW} \mathrm{h})$.The total cost of electricity would have to include Operation and Maintenance, including component replacements, which is of the order of $20 \%$ of the fixed cost, so amounting to $80 € / \mathrm{MW} \mathrm{h}$, which is close to competing with classical sources of electricity generation [35].

These estimates are based on the concepts and numbers explained along the paper, where optimization of a Fresnel Advanced power plant can be devised with the following data on efficiencies of the energy conversion chain, obtained from results that follow studies made in Sections 2-4:

Optical annual useful efficiency $=62 \%$.

Thermal capture efficiency $=78 \%$.

Cycle efficiency (minus self-consumption) $=39 \%$.

Overall (yearly integrated, solar to electricity) $=19 \%$.

Table 5

Fresnel-based solar field module description and cost.

\begin{tabular}{llc}
\hline Component & Material & Cost (k€) \\
\hline Structures & Steel & 100 \\
Mitrors & Glass \& Silver & 80 \\
Receiver window & Glass & 20 \\
Receiver tubes (+box) & Stainless steel & 100 \\
Tracking \& aux. & Electronics \& other & 25 \\
Outer piping & Steel & 25 \\
Total & 100 m collector & 350 \\
\hline
\end{tabular}

These values characterizing the energy transmission and conversion chain are somehow better than currently published data on Fresnel performance [67] what can be explained by the optimization process started after finding an appropriate heat carrier fluid $\left(\mathrm{CO}_{2}\right)$ without the strong limitations of other material, including water/steam, which is the fluid selected in said Ref. [67].

These values on the energy chain and the related investment cost are the main conclusions from this work. However, these results are expected to be improved with future work, particularly in the case of finding means for building a prototype to check the optical and thermal performance of different materials. This prototype would be based on the sound and comprehensive analysis presented in this paper, which mainly is the outcome of a systematic research exercise to feature properly the full energy conversion chain, from optics to thermodynamic cycles, with special emphasis in collecting the solar heat with the highest possible exergy and the simplest possible mechanical structures.

\section{Acknowledgements}

This work was funded by the Deanship of Scientific Research (DSR), King Abdulaziz University, Jeddah, under Grant No. 829012-D1434. The authors, therefore acknowledge with thanks DSR technical and financial support.

\section{References}

[1] Azofra D, Martínez E, Jiménez E, Blanco J, Saenz-Díez JC. Comparison of the influence of biomass, solar-thermal and small hydraulic power on the Spanish electricity prices by means of artificial intelligence techniques. Appl Energy 2014;121:28-37. ISSN 0306-2619 [15 May].

[2] Desideri U, Campana PE. Analysis and comparison between a concentrating solar and a photovoltaic power plant. Appl Energy 2014;113(January):422-33. ISSN 0306-2619.

[3] Desideri U, Zepparelli F, Morettini V, Garroni E. Comparative analysis of concentrating solar power and photovoltaic technologies: technical and environmental evaluations. Appl Energy 2013;102(February):765-84. ISSN 0306-2619.

[4] Tian $Y$, Zhao CY. A review of solar collectors and thermal energy storage in solar thermal applications. Appl Energy 2013;104(April):538-53. ISSN 03062619.

[5] Winter CJ, Sizmann RL, Vant Hull LL. Solar power plants: fundamentals, technology, systems economics. Berlin Heidelberg: Springer; 2011. ISBN 978 3-642-61245-9.

[6] Kalogirou S. Solar energy engineering: processes and systems. Academic Press 2013, ISBN 0-123-74501-2.

[7] Dang A. Concentrators: a review. Energy Convers Manage 1986;26(1):11-26 ISSN 0196-8904

[8] Muñoz J, Martinez-Val JM, Ramos A. Thermal regimes in solar-thermal linear collectors. Solar Energy 2011;85(5):857-70, ISSN 0038-092X.

[9] Abbas R, Muñoz J, Martínez-Val JM. Steady-state thermal analysis of an innovative receiver for linear Fresnel reflectors. Appl Energy 2012:92(April):503-15, ISSN 0306-2619.

[10] Fernández-García A, Zarza E, Valenzuela L, Pérez M. Parabolic-trough solar collectors and their applications. Renew Sustain Energy Rev 2010;14(7):1695721, ISSN 1364-032

[11] Montes MJ, Abanades A, Martinez-Val JM. Thermofluidynamic model and comparative analysis of parabolic trough collectors using oil, water/steam or molten salt as heat transfer fluids. J Solar Energy Eng (ASME) 2010;132(2):1-7.

[12] Stultz S, Kitto J. Steam: its generation and use, 41st ed. Babcock \& Wilcox Compdny; 2005, ISBN 0963457012.

[13] Montes MJ, Abanades A, Martinez-Val J, Valdés M. Solar multiple optimization for a solar-only thermal power plant, using oil as heat transfer fluid in the parabolic trough collectors. Solar Energy 2009;83(12):2165-76.

[14] Avila-Marin Antonio L, Fernandez-Reche Jesus, Tellez Felix M. Evaluation of the potential of central receiver solar power plants: configuration, optimization and trends. Appl Energy 2013;112(December):274-88, ISSN 0306-2619.

[15] Rovira A, Muñoz-Antón J, Montes M], Martínez-Val JM. Optimization of Brayton cycles for low-to-moderate grade thermal energy sources. Energy 2013;55:403-16.

[16] Shañikaì Ganesh $N$, Srinivivas T. Design and modeling of low temperature solâi thermal power station. Appl Energy 2012;91(1):180-6, ISSN 0306-2619.

[17] Peng Shuo, Hong Hui, Wang Yanjuan, Wang Zhaoguo, Jin Hongguang. Offdesign thermodynamic performances on typical days of a $330 \mathrm{MW}$ solar aided coal-fired power plant in China. Appl Energy 2014;130(1):500-9, ISSN 0306 2619 
[18] Antipova Ekaterina, Boer Dieter, Cabeza Luisa F, Guillén-Gosálbez Gonzalo, Jiménez Laureano. Multi-objective design of reverse osmosis plants integrated with solar Rankine cycles and thermal energy storage. Appl Energy 2013;102(February):1137-47, ISSN 0306-2619.

[19] Jafarian Mehdi, Arjomandi Maziar, Nathan Graham J. The energetic performance of a novel hybrid solar thermal \& chemical looping combustion plant. Appl Energy 2014;132:74-85, ISSN 0306-2619 [1 November].

[20] Choudhury C, Sehgal HK. A fresnel strip reflector-concentrator for tubular solar-energy collectors. Appl Energy 1986;23(2):143-54, ISSN 0306-2619.

[21] Negi B, Mathur S, Kandpal T. Optical and thermal performance evaluation of a linear Fresnel reflector solar concentrator. Solar Wind Technol 1989:6(5):589-93.

[22] Negi B, Kandpal T, Mathur S. Designs and performance characteristics of a linear Fresnel reflector solar concentrator with a flat vertical absorber. Solar Wind Technol 1990;7(4):379-92.

[23] Mathur S, Kandpal T, Negi B. Optical design and concentration characteristics of linear Fresnel reflector solar concentrators-1. Mirror elements of varying width. Energy Convers Manage 1991;31(3):205-19.

[24] Mathur S, Kandpal T, Negi B. Optical design and concentration characteristics of linear Fresnel reflector solar concentrators-II. Mirror elements of equal width. Energy Convers Manage 1991;31(3):221-32, ISSN 0196-8904.

[25] Mills DR, Morrison GL. Compact linear Fresnel reflector solar thermal powerplants. Solar Energy 2000;68(3):263-83.

[26] Häberle A, Zahler C, Lerchenmüller H, Mertins M, Wittwer C, Trieb F, et al. The Solarmundo line focussing Fresnel collector, optical and thermal performance and cost calculations. In: 11th International SolarPACES symposium on solar thermal concentrating technologies. Zurich, Switzerland; 2002

[27] Morin G, Platzer W, Eck M, Uhlig R, Häberle A, Berger M, et al. Road map towards the demonstration of a linear Fresnel collector using a single tube receiver. In: 13th International SolarPACES symposium on solar thermal concentrating technologies. Las Vegas, USA; 2006. p. 20-3.

[28] Hautmann G, Selig M, Mertins M. First European linear Fresnel power plant in operation - operational experience \& outlook. In: 15th International SolarPACES symposium on solar thermal concentrating technologies. Berlin, Germany; 2009.

[29] Dersch J, Morin G, Eck M, Häberle A. Comparison of linear Fresnel and parabolic trough collector systems-system analysis to determine break even costs of linear Fresnel collectors. In: 15th International SolarPACES symposium on solar thermal concentrating technologics. Bcrlin, Germany; 2009.

[30] Singh P, Sarviya R, Bhagoria J. Thermal performance of linear Fresnel reflecting solar concentrator with trapezoidal cavity absorbers. Appl Energy $2010 ; 87(2): 541-50$

[31] Novatec-Solar. Technical Data NOVA-1, Puerto Errado; $2011<$ http://www. novatec-biosol.com/>.

[32] Bernhard R, Hein S, de Lalaing J, Eck M, Eickhoff M, pfänder M, et al. Linear Fresnel collector demonstration on the PSA part II - commissioning and firs performance tests. In: 14th International SolarPACES symposium on solar thermal concentrating technologies. Las Vegas; 2008.

[33] Rodriguez-Garcia M, Marquez-Payes JM, Biencinto M, Adler JP, Diez LE. First experimental results of a solar PTC facility using gas as the heat transfer fluid. In: SolarPACES 2009, 15-18 September. Berlin, Germany.

[34] Muñoz-Anton J, Biencinto M, Zarza E, Díez LE. Theoretical basis and experimental facility for parabolic trough collectors at high temperature using gas as heat transfer fluid. Appl Energy 2014;135:373-81. 15 December.

[35] Turchi $C$. Current and future costs of parabolic trough and power tower systems in the US Indaket. NREL/CP-5500-49303;2010.

[36] Merrit FS, editor. Structural steel designers' handbook. New York: McGrawHill; 1972.

[37] Ramaswamy MA, et al. Engineering economic policy assessment of concentrated solar thermal power technologies for India. Center for Study of Science Technology and Policy; Bangalore, India; 2012 CSTEP/E/7 2012.

[38] Atkearny. Solar Themal Electricity $2025<$ http://www.estelasolar.eu/ fileadmin/ESTELAdocs/documents/Cost_Roadmap/2010-06\%20$\% 20$ Solar\%20Thermal\%20Electricity\%202025\%20-\%20ENG.pdf> October 2013].

[39] Abbas R, Montes MJ, Piera M, Martínez-Val JM. Solar radiation concentration features in Linear Fresnel Reflector arrays. Energy Convers Manage 2012;54(1):133-44, ISSN 0196-8904.

[40] Chu SX, Liu LH. Analysis of terrestrial solar radiation exergy. Solar Energy 2010;83:1390-404.

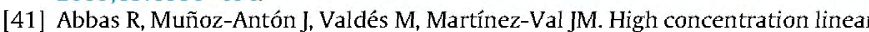
Fresnel reflectors. Energy Convers Manage 2013;72(August):60-8, ISSN $0196-$ 8904.
[42] System Advisor Model (SAM) of NREL <https://sam.nrel.gov/>

[43] Martinez-Val JM, et al. Linear receiver of concentrated solar radiation. Patent number ES 2345759 B2, Spain; 2010.

[44] Martinez-Val JM, et al. Solar radiation concentration system, with linear mirrors and receiver. Patent number ES 2345427 B2, Spain; 2010. PCT/ ES2011/000163.

[45] Rigollier C, Bauer O, Wald L. On the clear sky model of the ESRA-European Solar Radiation Atlas-with respect to the Heliosat method. Solar Energy 2000;68(1):33-48.

[46] Buie D, Monger AG. The effect of circumsolar radiation on a solar concentrating system. Solar Energy 2004;76(1-3):181-5, ISSN 0038-092X.

[47] Plataforma Solar de Almeria, $2013<$ http:/www.psa.es/webesp/instalaciones/ receptor.php>.

[48] Odeh Saad D, Morrison GL. Optimization of parabolic trough solar collector system. Int J Energy Res 2006:30:259-71.

[49] Forristal R. Heat transfer analysis and modelling of a parabolic trough solar receiver implemented in engineering equation solver, NREL Technical Report NREL/TP-550-34169, Golden, Colorado, USA; 2003.

[50] Muñoz-Antôn J, Abbas R, Martinez-Val JM, Montes MJ. Going further with Fresnel receiver: new design window for direct steam generation, SolarPACES 2013, 17-20 September, Las Vegas, USA.

[51] Gil A, Medrano M, Martorell I, Lázaro A, Dolado P, Zalba B, et al. State of the art on high temperature thermal energy storage for power generation. Part 1. Concepts, materials and modellization. Renew Sustain Energy Rev 2010;14(1):31-55.

[52] Medrano Marc, Gil Antoni, Martorell Ingrid, Potau Xavi, Cabeza Luisa F. State of the art on high-temperature thermal energy storage for power generation. Part 2 -case studies. Renew Sustain Energy Rev 2010;14(1):56-72.

[53] Herrmann Ulf, Kelly Bruce, Price Henry. Two-tank molten salt storage for parabolic trough solar power plants. Energy 2004;29(5-6):883-93.

[54] Relloso Sergio, Delgado Emilio. Experience with molten salt thermal storage in a commercial parabolic trough plant. Andasol-1 commissioning and operation. In: Proceedings of 15th international SolarPACES symposium on solar thermal concentrating technologies. Berlin, Germany; 2009

[55] Rovira A, Montes MJ, Valdes M, Martínez-Val JM. Energy management in solar thermal power plants with double thermal storage system and subdivided solar field. Appl Energ 2011;88:4055-12.

[56] Wittmann $M$ et al. Methodology for optimized operation strategies of solar thermal power plants with integrated heat storage. Solar Energy 2010. http:/ dx.doi.org/10.1016/i.solener.2010.11.024.

[57] Rosen MA, Dincer I. Exergy methods for assessing and comparing thermal storage systems. Int J Energy Res 2003;27:415-30.

[58] Tamme R, Laing D, Steinmann WD. Advanced thermal energy storage technology for parabolic trough. I Sol Energy Eng 2004;126:794-7.

[59] Yang Z, Garimella SV. Thermal analysis of solar thermal energy storage in a molten-salt thermocline. Solar Energy 2010;84:974-85.

[60] Guillot Stéphanie, Faik Abdessamad, Rakhmatullin Aydar, Lambert Julien, Veron Emmanuel, Echegut Patrick, et al. Corrosion effects between molten salts and thermal storage material for concentrated solar power plants. Appl Energy 2012:94(June):174-81, ISSN 0306-2619.

[61] Rovira Antonio, José Montes María, Valdes Manuel, Martínez-Val José María. Energy management in solar thermal power plants with double thermal storage system and subdivided solar field. Appl Energy 2011;88(11):4055-66, ISSN 0306-2619.

[62] Flueckiger Scott M, Iverson Brian D, Garimella Suresh V, Pacheco James E. System-level simulation of a solar power tower plant with thermocline thermal energy storage. Appl Energy 2014;113(January):86-96, ISSN 03062619.

[63] Yang Zhen, Garimella Suresh V. Cyclic operation of molten-salt thermal energy storage in thermoclines for solar power plants. Appl Energy 2013:103(Match):256-65, ISSN 0306-2619.

[64] Peng Qiang, Yang Xiaoxi, Ding Jing, Wei Xiaolan, Yang Jianping. Design of new molten salt thermal energy storage material for solar thermal power plant. Appl Energy 2013;112(December):682-9, ISSN 0306-2619.

[65] Therminol, 2012 Heat Transfer Fluids by Solutia <http://www.therminol.com>.

[66] Muñoz J, Martínez-Val JM, Abbas R, Abánades A. Dry cooling with night cool storage to enhance solar power plants performance in extreme conditions areas. Appl Energy 2012;92:429-36.

[67] Wagner MJ. Results and comparison from SAM Linear Fresnel performance model, NREL/CP 5500-54578; 2012 <http://www.osti.gov/bridge> 